Universidad de Lima

Facultad de Ciencias Empresariales y Económicas

Carrera de Marketing

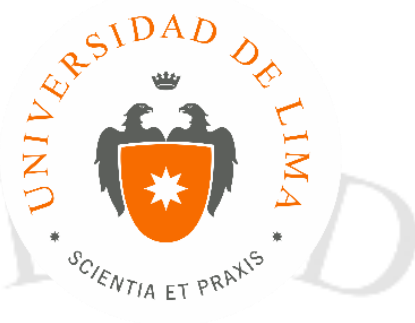

\title{
GESTIÓN DEL SERVICIO Y CANALES DE VENTA DEL SEGURO COMPLEMENTARIO DE TRABAJO DE RIESGO EN MAPFRE PERÚ
}

Trabajo de suficiencia profesional para optar el Título Profesional de Licenciado en

Marketing

David Foinquinos Diaz

Código 20120508

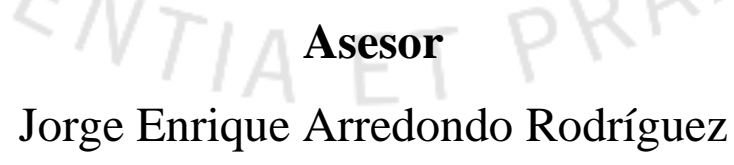

Lima - Perú

Noviembre del 2018 


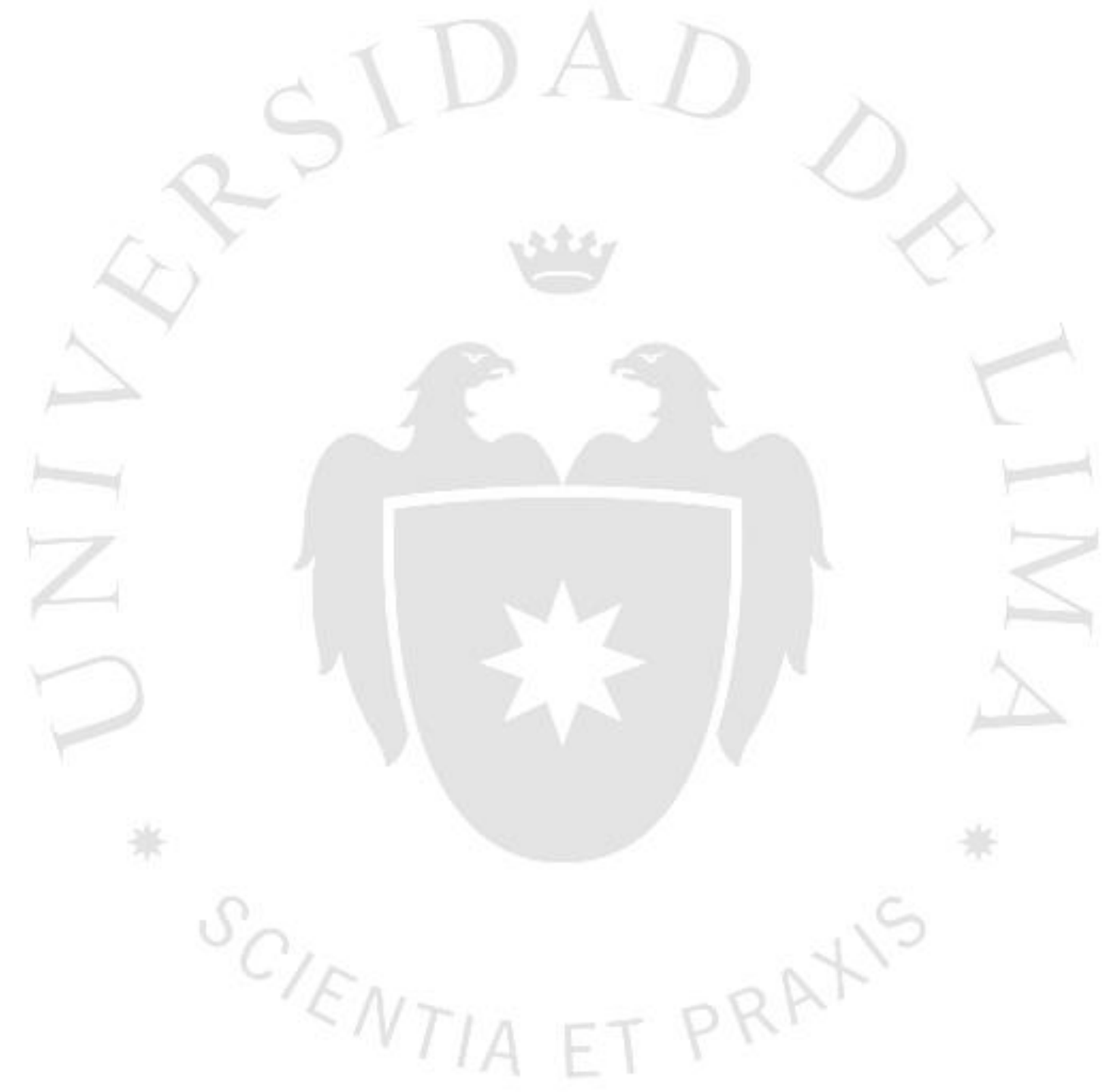




\section{GESTIÓN DEL SERVICIO Y CANALES DE}

VENTA DEL SEGURO COMPLEMENTARIO DE TRABAJO DE RIESGO EN MAPFRE PERÚ 


\section{TABLA DE CONTENIDO}

\section{INTRODUCCIÓN}

CAPÍTULO I: CONTEXTO DE LA EMPRESA

1.1 Descripción y antecedentes de la industria en la que se desempeña la empresa.....2

1.2 Descripción de la empresa en cuanto a los accionistas, estructura organizacional, unidades de negocio, marcas y mezcla de producto...............................................

1.3 Descripción del mercado y sus segmentos .................................................

1.4 Cuantificación de la industria en volumen de unidades y valor de venta ..............11

1.5 Identificación, descripción y participación de mercado de competidores directos.

\section{CAPÍTULO II: DIAGNÓSTICO DEL MARKETING ESTRATÉGICO DE LA}

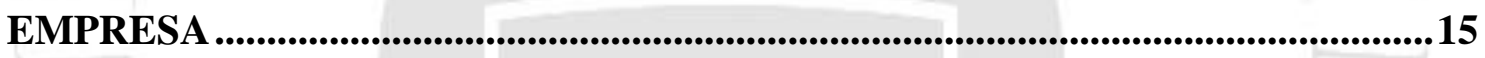

2.1 Diagnóstico y análisis de la estrategia genérica: ........................................... 15

2.2 Descripción y análisis de las ventajas competitivas: ...................................... 16

2.3 Descripción y análisis de la estrategia de marketing corporativo: ...................... 17

2.4 Descripción y análisis de las estrategias competitivas de marketing:.................. 18

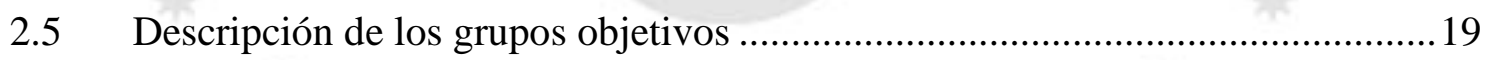

2.6 Descripción del posicionamiento de la empresa .............................................21

2.7 Descripción de la creación del Brand Equity ................................................22

CAPITULO III: DESCRIPCIÓN DEL CASO O PROBLEMA.............................23

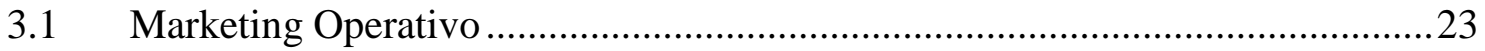

3.1.1 Descripción del servicio básico o principal ….................................................23

3.1.2 Descripción de la Flor de servicios complementarios .......................................2

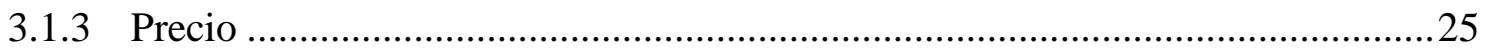

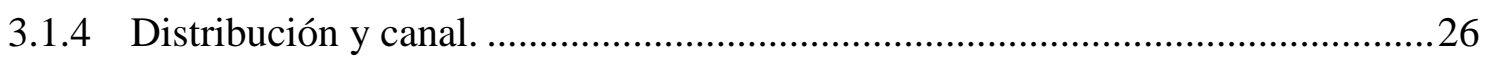

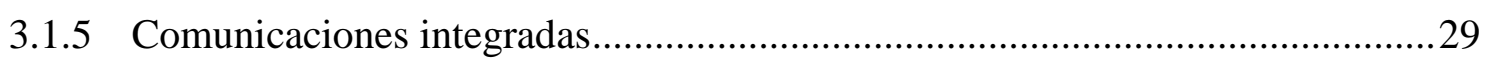




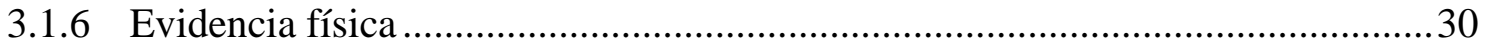

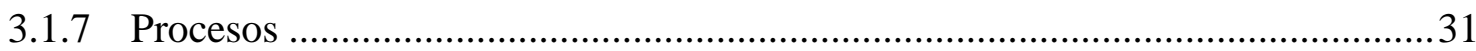

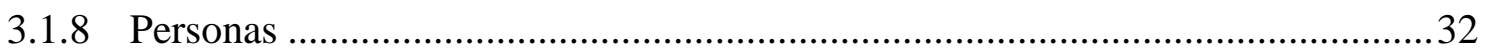

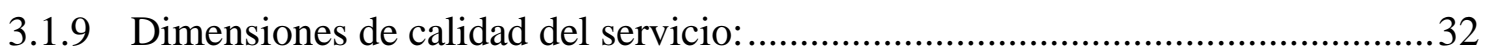

3.1.10 Sistema de medición de Calidad del Servicio de Mapfre: .................................. 33

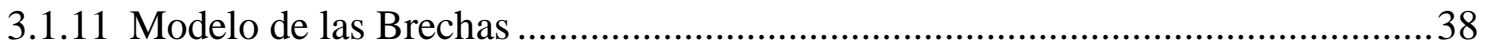

3.2 Evolución de la venta por canales, descripción del problema: ...........................41

3.2.1 Análisis situación actual de la venta por canales: ............................................42

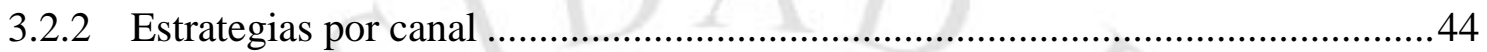

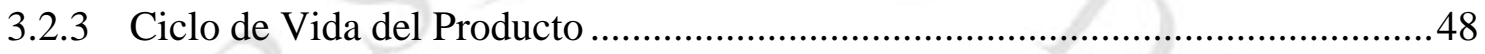

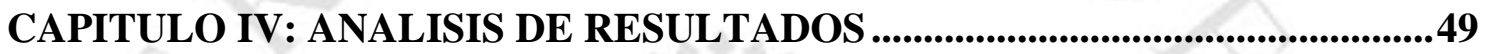

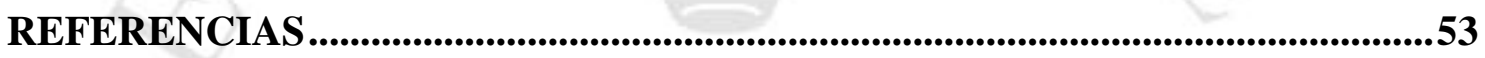

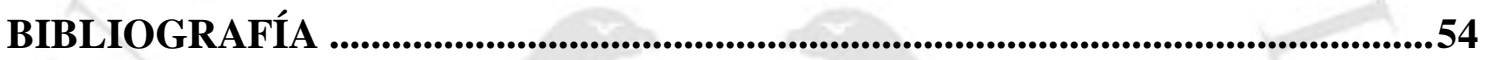




\section{ÍNDICE DE TABLAS}

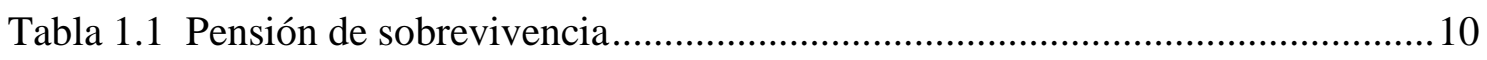

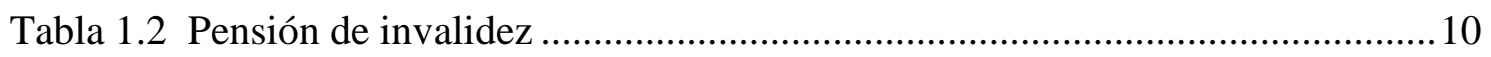

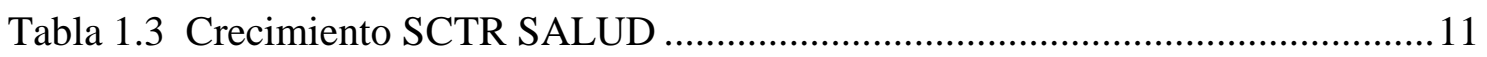

Tabla 1.4 Crecimiento SCTR PENSIONES …........................................................... 11

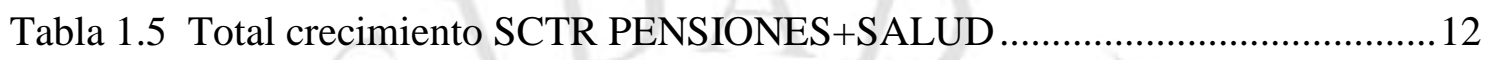

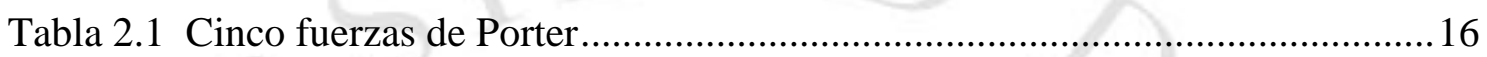

Tabla 2.2 Segmentación de clientes SCTR por monto de primas anuales ..................... 19

Tabla 2.3 Segmentación de clientes SCTR Matriz Actividad vs. Monto de Primas .....20

Tabla 2.4 Agrupación de los canales de venta............................................................20

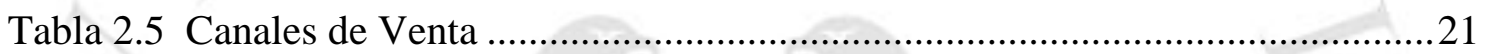

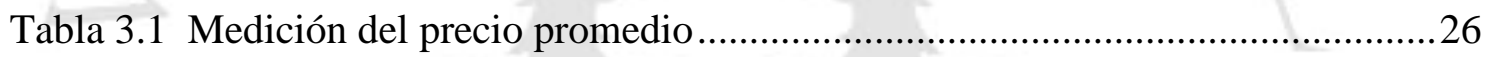

Tabla 3.2 Flujograma del servicio básico o principal .............................................. 31

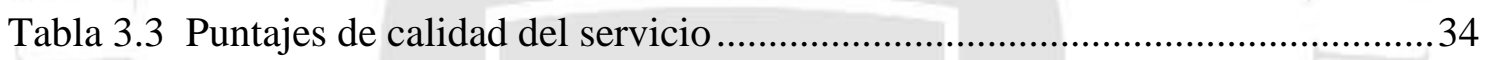

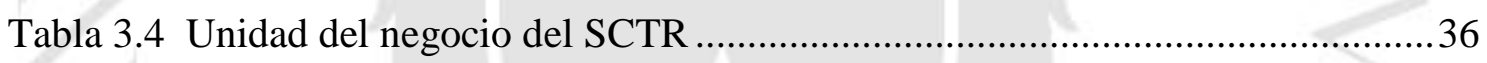

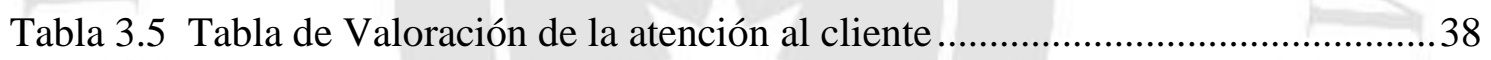

Tabla 3.6 Evolución de distribución porcentual por canal de ventas ............................41

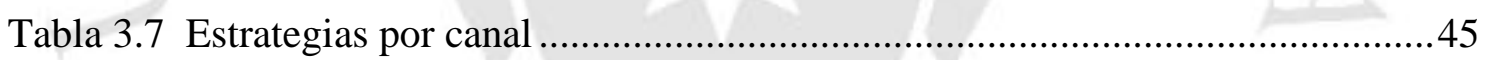




\section{ÍNDICE DE FIGURAS}

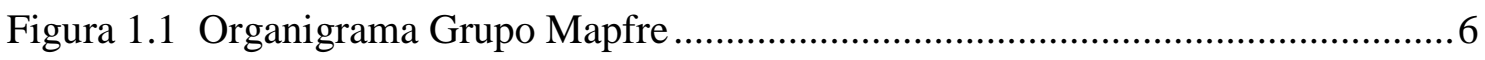

Figura 1.2 Empresas: Principales productos ........................................................... 7

Figura 1.3 Personas: Principales productos .......................................................... 7

Figura 1.4 Entidades empleadoras obligadas a contratar el SCTR .............................. 8

Figura 1.5 Coberturas Seguro Complementario de Trabajo de Riesgo .......................... 9

Figura 1.6 Competidores directos SCTR PENSIONES ........................................ 12

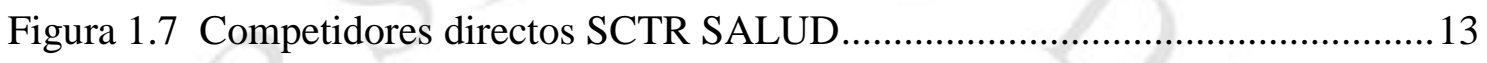

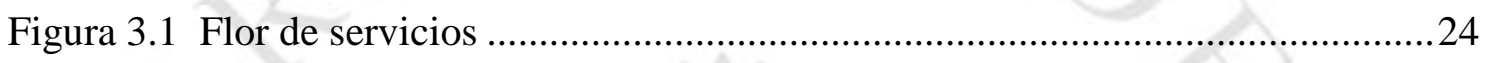

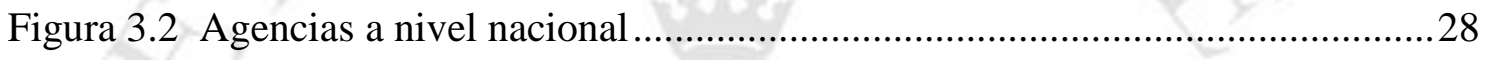

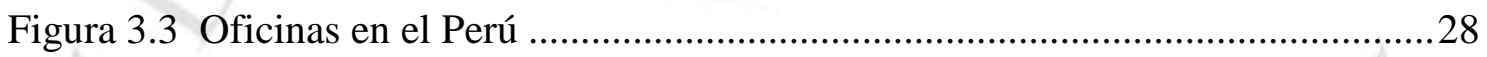

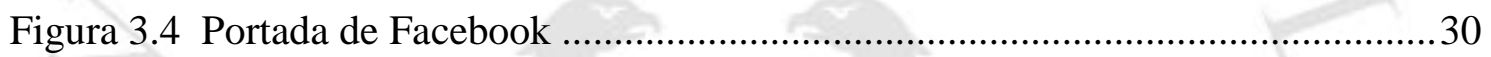

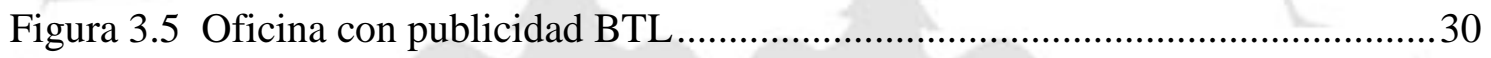

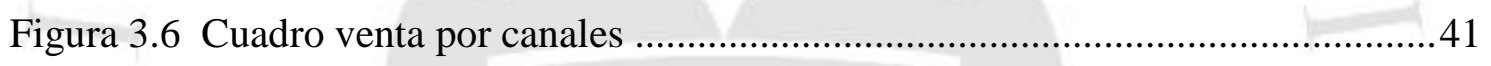

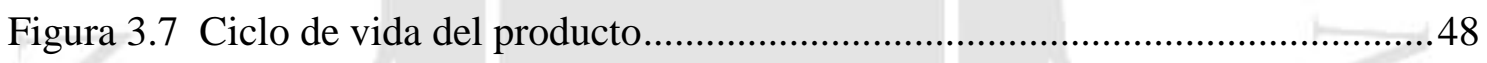




\section{INTRODUCCIÓN}

Mapfre es una empresa multinacional española dedicada al sector de seguros, siendo la primera aseguradora global de Latinoamérica con presencia en todos los países de la región. En Perú es la tercera aseguradora por volumen de primas, con una facturación el año 2017 de S/. 1,735 Millones y una participación del 13.7\% de mercado, estando presente en todos los subsectores del negocio de seguros con excepción de rentas vitalicias de jubilación.

Una de las líneas de negocio en que Mapfre participa es la del Seguro Complementario de Trabajo de Riesgo (SCTR). Este es un seguro obligatorio por la Ley 26790 y que brinda cobertura contra accidentes de trabajo y enfermedades profesionales a los trabajadores de las empresas que realicen actividades de alto riesgo definidas en la Ley tales como: Minería, construcción, metalmecánica, madera, electricidad, gas, pesca entre otros sectores.

El presente trabajo desarrolla la gestión del servicio y de los canales de venta del Seguro Complementario de Trabajo de Riesgo (SCTR) dentro de Mapfre Perú. En el mismo se analiza el mercado y la problemática de los últimos años, además se analiza cómo es que se gestiona el servicio de Mapfre Perú y se proponen alternativas para continuar desarrollando el servicio y creciendo en los diversos canales y segmentos. 


\section{CAPÍTULO I: CONTEXTO DE LA EMPRESA}

\subsection{Descripción y antecedentes de la industria en la que se desempeña la empresa}

Desde un punto de vista general, el contrato de seguro es aquel por el que el asegurador se obliga, mediante el cobro de una prima y para el caso de que se produzca el evento cuyo riesgo es objeto de cobertura, a indemnizar, dentro de los límites pactados, el daño producido al asegurado, o a satisfacer un capital, una renta $\mathrm{u}$ otras prestaciones convenidas.

Este contrato se caracteriza por ser, fundamentalmente, consensual, bilateral, aleatorio, oneroso, de adhesión y por estar basado en la buena fe.

Las compañías de seguros son las empresas dedicada a la práctica del seguro. Las características esenciales de estas son:

- Exclusividad de actuación.

- Sometimiento a normas de vigilancia oficial.

- Operaciones en masa.

- $\quad$ Exigencia de capital inicial.

- Garantía financiera.

En el Perú el mercado de Seguros está constituido a junio de 2018 por 18 empresas con una facturación a dicho mes de S/.6,089 millones, y una facturación durante el año 2017 de S/11,327 Millones. A junio 2018, 5 compañías concentran el 89.5\% del mercado, siendo compañías que participan en la mayoría de productos, las otras 13 compañías son llamadas de nicho, pues se concentran en mercados específicos con productos como: Desgravamen, Vida Masiva (Banca seguro), Rentas de Jubilación, Accidentes Personales entre otras.

Las 5 principales compañías y su participación a junio 2018 son:

- Rímac: con una participación de 30\%, perteneciente al Grupo Breca.

- Pacifico: con una participación de $26.5 \%$, perteneciente al Grupo Credicorp.

- Mapfre: con una participación de $14.7 \%$, perteneciente al Grupo Mapfre 
- La Positiva: con una participación de $11.1 \%$, perteneciente a diversos accionistas nacionales, recientemente adquirido el $51 \%$, por la aseguradora portuguesa Fidellidade.

- Interseguros: Con una participación de 7.1\%, perteneciente al grupo Intercorp, a diferencia de las cuatro primeras esta compañía se concentra principalmente en los productos de Rentas vitalicias.

Se puede observar que de las 5 compañías que concentran casi el $90 \%$ del mercado, 3 de ellas, están ligados a los principales grupos financieros del Perú (Breca, Credicorp e Intercorp).

Durante el año 2017 el mercado de seguros creció apenas 0.63\%, motivado por:

- La inestabilidad política la cual tiene un fuerte impacto en la contratación pública y en la privada derivada del desarrollo de la infraestructura.

- Fuerte guerra de precios en el negocio corporativo, que ha desencadenado una baja general de tasas.

- Nulo crecimiento del sector asegurador como consecuencia de la desconfianza en las perspectivas económicas y el efecto paralizante de inversiones de todos los acontecimientos desencadenados por el escándalo Odebretch.

- $\quad$ El fenómeno del niño costero.

Durante el primer semestre del 2018 el mercado crece $11.44 \%$, saliendo del estancamiento del año anterior motivado principalmente por:

- La mejora del clima política y la recuperación fiscal.

- Algunas variables económicas están mejorando, con la demanda interna, la inflación y las exportaciones como principales exponentes.

- Las catástrofes naturales a nivel mundial ocurridas el 2017 (Huracanes, terremotos, niño costero en Perú), ha motivado que los precios de los reaseguradores suban lo cual se traduce en aumento de tarifas especialmente en Riesgos Generales.

Cabe destacar que el Estado también participa en el mercado de Seguros a través de la seguridad Social.

Los seguros pueden estar clasificados como seguros de daños a personas y seguros contra daños materiales. 
En los seguros que cubren daños a personas, la persona queda cubierta ante cualquier situación o imprevisto que le afecte. Estos abarcan los seguros de vida, los seguros médicos privados y accidentales, los cuales cubren al asegurado en caso de enfermedad y la integridad de la persona ante un accidente. Los seguros contra daños materiales cubren de manera parcial o total la pérdida patrimonial a causa de un siniestro o catástrofe, pudiendo ser seguros para el hogar, seguros contra robos, seguros contra automóviles, seguros contra incendios y también de responsabilidad civil.

El presente trabajo se concentrará en el Seguro Complementario de Trabajo de Riesgo (SCTR), que es un seguro obligatorio que cubre contra accidentes de trabajo y enfermedades profesionales a los trabajadores de las empresas obligadas por Ley, tales como Construcción, Minería, Metal Mecánica, Pesca, Puertos, entre otros.

El SCTR es un seguro que cubre a Personas y es contratado por Empresas para sus trabajadores.

1.2 Descripción de la empresa en cuanto a los accionistas, estructura organizacional, unidades de negocio, marcas y mezcla de producto

El Grupo Mapfre Perú es propiedad de Mapfre Internacional que es el principal accionista con más del $90 \%$. Se describe el Grupo Mapfre a nivel internacional para luego describirlo en el Perú.

\section{$\underline{\text { Mapfre en el mundo }}$}

Mapfre busca ser la aseguradora global de confianza. Ocupa una posición de referencia en los principales mercados mundiales. Es el primer grupo asegurador multinacional en América Latina. Está entre las 10 primeras aseguradoras en Europa y en el Top 20 de seguros de automóvil en Estados Unidos. Mapfre a nivel mundial facturó el año 2017: 27,985 millones de euros.

\section{$\underline{\text { Mapfre En el Perú }}$}

En el Perú tiene 22 años de trayectoria y es el grupo asegurador con el mayor respaldo internacional, contando con la mayor red de oficinas del país (más de 60 oficinas a nivel nacional) y con más de 1 millón de asegurados a través de nuestras sus cuatro empresas:

- MAPFRE Perú Seguros Generales 
- MAPFRE Perú Vida

- Corporación Funeraria (propietaria de Finisterre y Agustín Merino)

- MAPFRE EPS.

El grupo Mapfre Perú conformado por las compañías antes descritas facturo el año 2017 S/1,735 millones, con una utilidad después de impuestos de S/156 millones.

Las empresas del Grupo Mapfre Perú, organizan en una sola estructura pudiendo una unidad de negocio tener productos de diferentes empresas de acuerdo a la especialidad, por ejemplo, la Unidad de Salud, tendrá productos de tres compañías.

La compañía está estructurada de la siguiente manera:

Área Técnicas: que cuenta con Unidades de Negocio que son las que gerencia los productos, su preció, características, volumen de ventas y resultado técnico. Las unidades de Negocio son: Vida, Riesgos del Trabajo, Salud, Automóviles, Riesgos Generales, Centros Médicos, Cauciones, Decesos, Funerarias y Cementerios.

Área Comercial: diferenciada por tipo cliente y distribución geográfica, maneja la distribución y venta de los productos, cuenta con las siguientes divisiones:

- Grandes Cuentas, encargado de los negocios corporativos y grandes corredores del mercado.

- Cuentas Institucionales, encargado de negocios del estado.

- Canales No Tradicionales, encargados de banca seguros, tiendas por departamentos, concesionarios, entre otros.

- $\quad$ Red Territorial, encargado de la atención de oficinas a nivel nacional tanto para corredores, los cuales están asignados geográficamente, así como para venta directa. Se divide en Subcentrales: Lima, Norte, Sur, Centro Lima, Centro Provincias.

- $\quad$ Redes Afectas, al mes de diciembre de 2017 Mapfre contaba con 1878 agentes distribuidos en redes comerciales especializadas por productos (decesos, salud, SCTR, Vida) y multi productos (red plaza, red digital, cross), estos agentes se distribuyen geográficamente en las oficinas de Mapfre.

Del Área comercial además depende la unidad de Clientes, encargada de la Publicidad, y Promoción de la compañía y productos, además de CRM. 
Área Financiera y Medios, a cargo de las finanzas, contabilidad, infraestructura, compras y logística.

Área de Tecnología de Información y Procesos, encargada de los sistemas y mejoramiento del flujo de procesos.

Área de Operaciones, encargada de procesos masivos de emisión y siniestros además de la Central Telefónica (SI24) y cobranzas.

Adicionalmente y reportando directamente al CEO se encuentra Recursos Humanos y Asesoría Jurídica.

Figura 1.1

Organigrama Grupo Mapfre

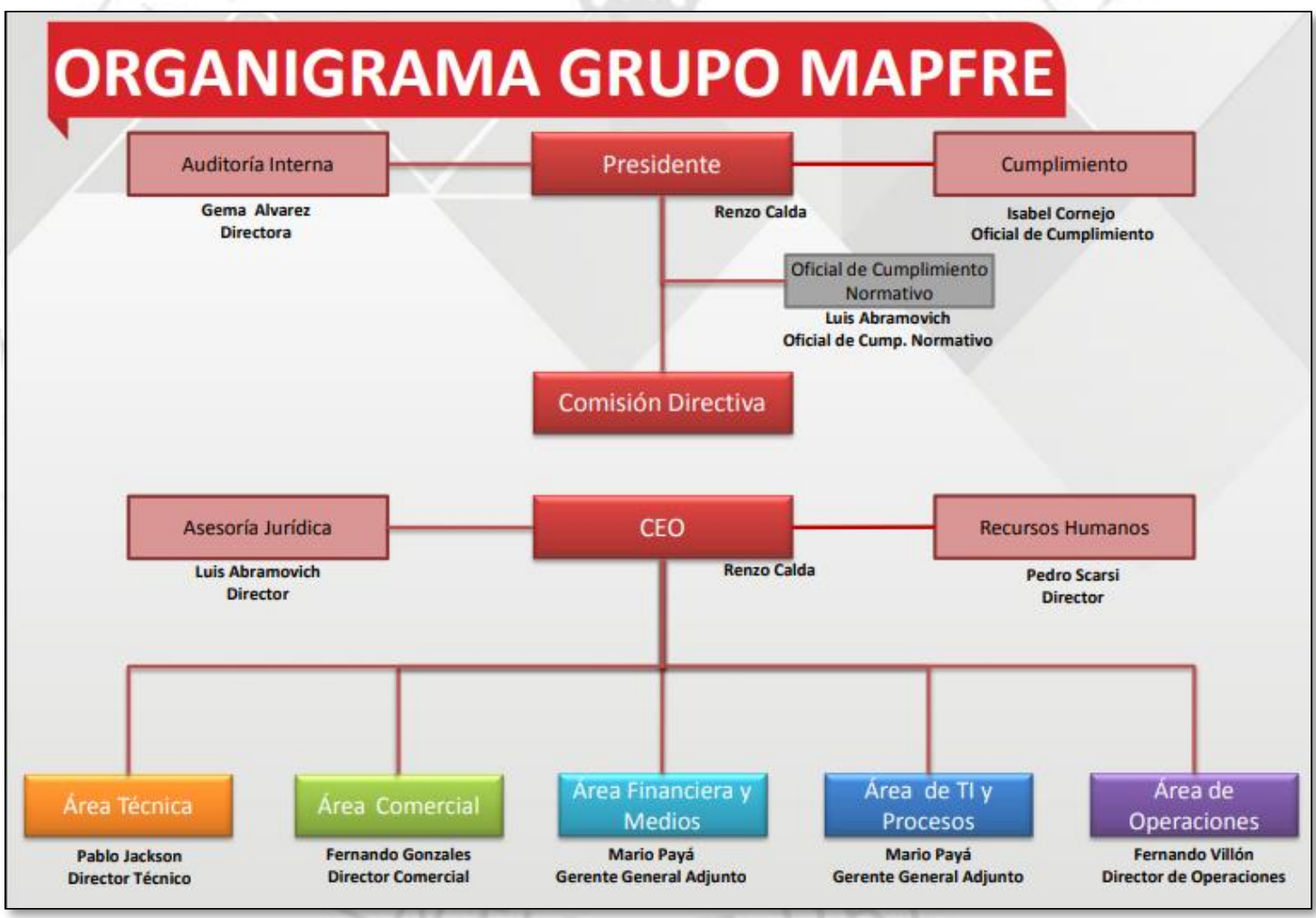

Fuente: Mapfre Perú (2018) 
Los productos que comercializa Mapfre se dividen en Empresas y Personas:

Figura 1.2

Empresas: Principales productos

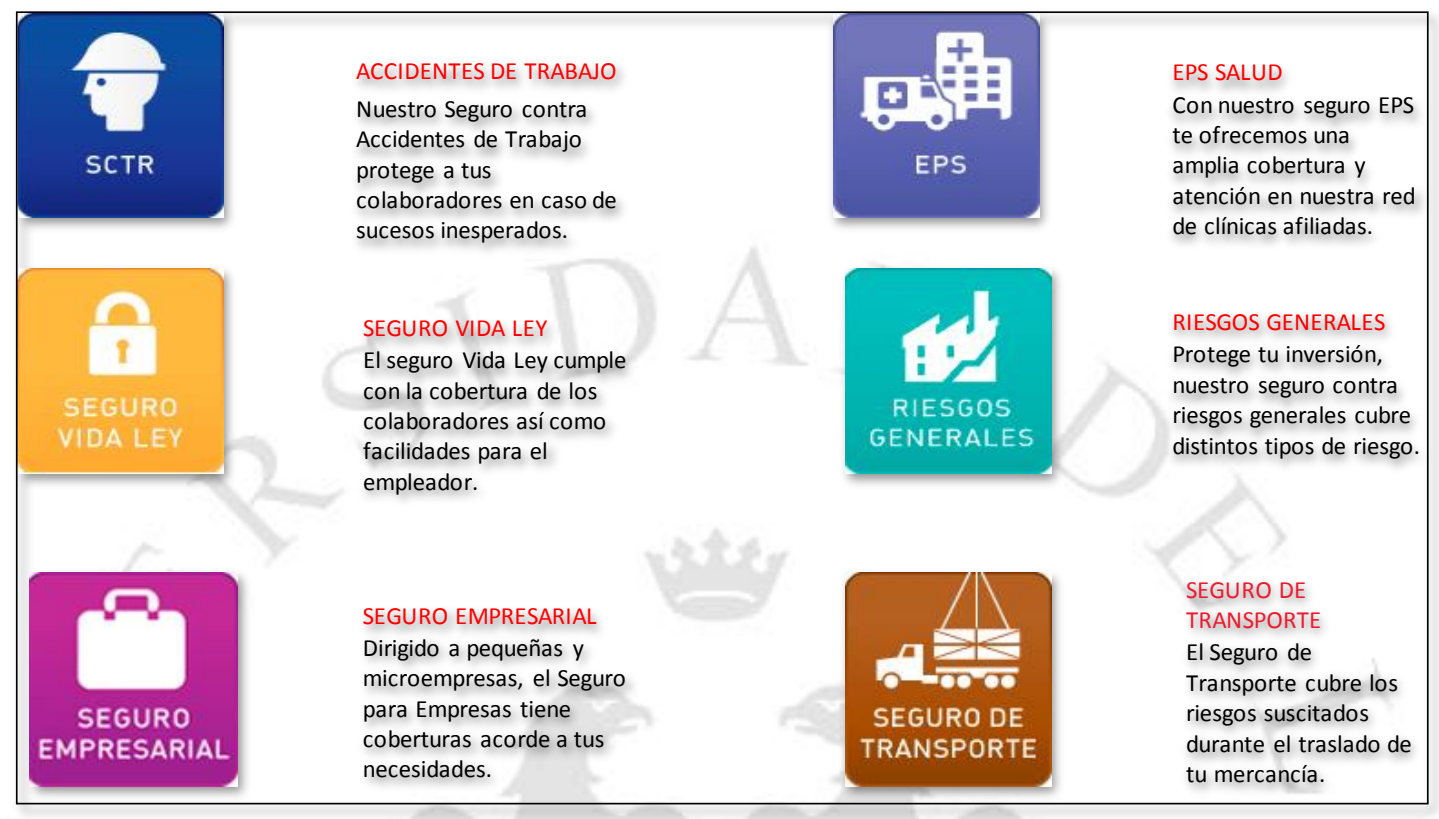

Fuente: Mapfre Perú (2018)

Figura 1.3

Personas: Principales productos

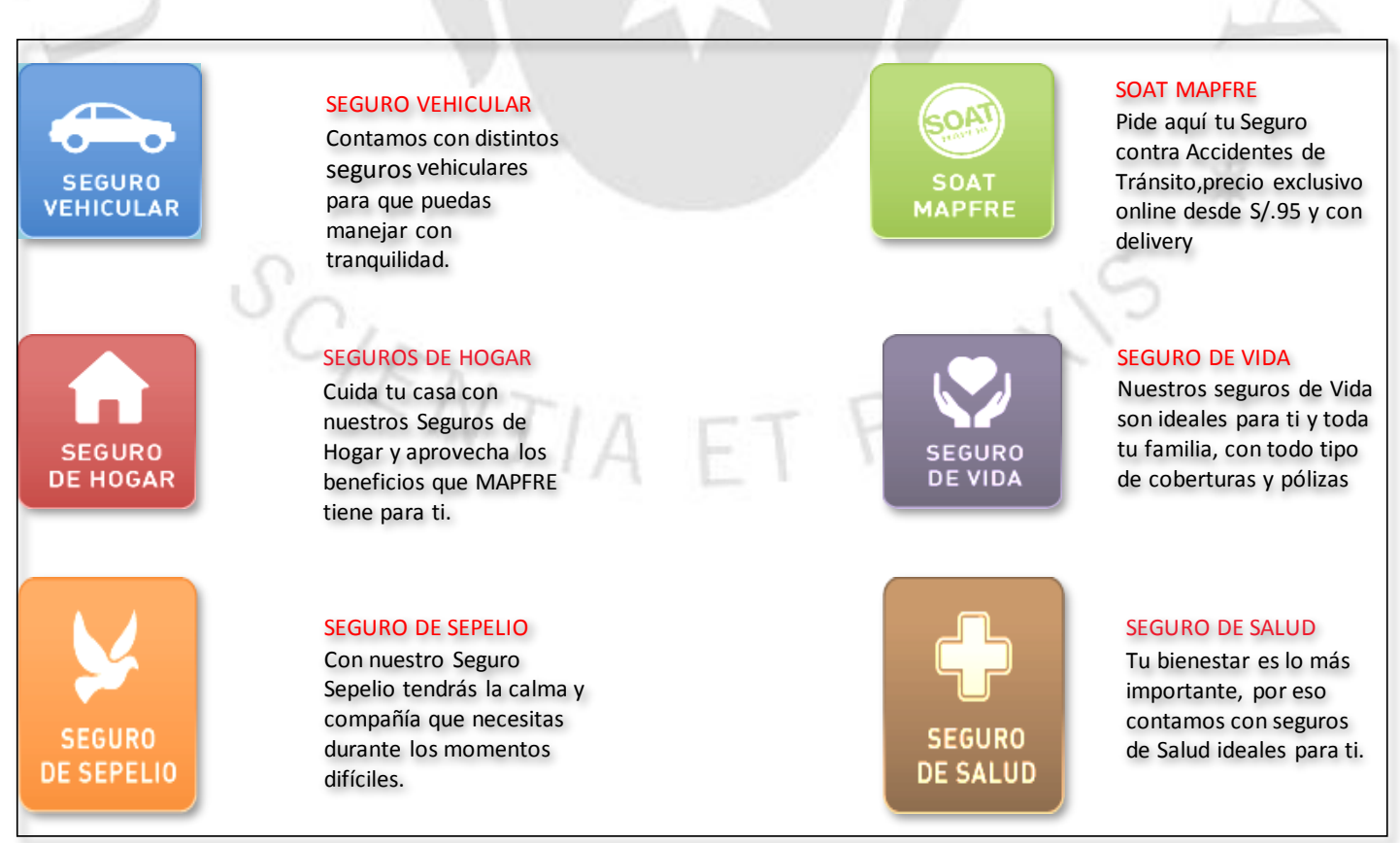

Fuente: Mapfre Perú (2018) 


\subsection{Descripción del mercado y sus segmentos}

\section{El mercado de SCTR:}

El Seguro Complementario de Trabajo de Riesgo (SCTR) se creó mediante la Ley 26790, Ley de Modernización de la Seguridad Social en Salud en el año 1997.

Es un Seguro que otorga cobertura por accidentes de trabajo y enfermedades profesionales.

Es obligatorio para las empresas que realizan actividades económicas de alto riesgo descritas Anexo $\mathrm{N}^{\circ} 5$ del D.S. $\mathrm{N}^{\circ}$ 009-97-SA. Las actividades obligadas a contratar el seguro son:

Entidades empleadoras obligadas a contratar el SCTR

Figura 1.4

Entidades empleadoras obligadas a contratar el SCTR

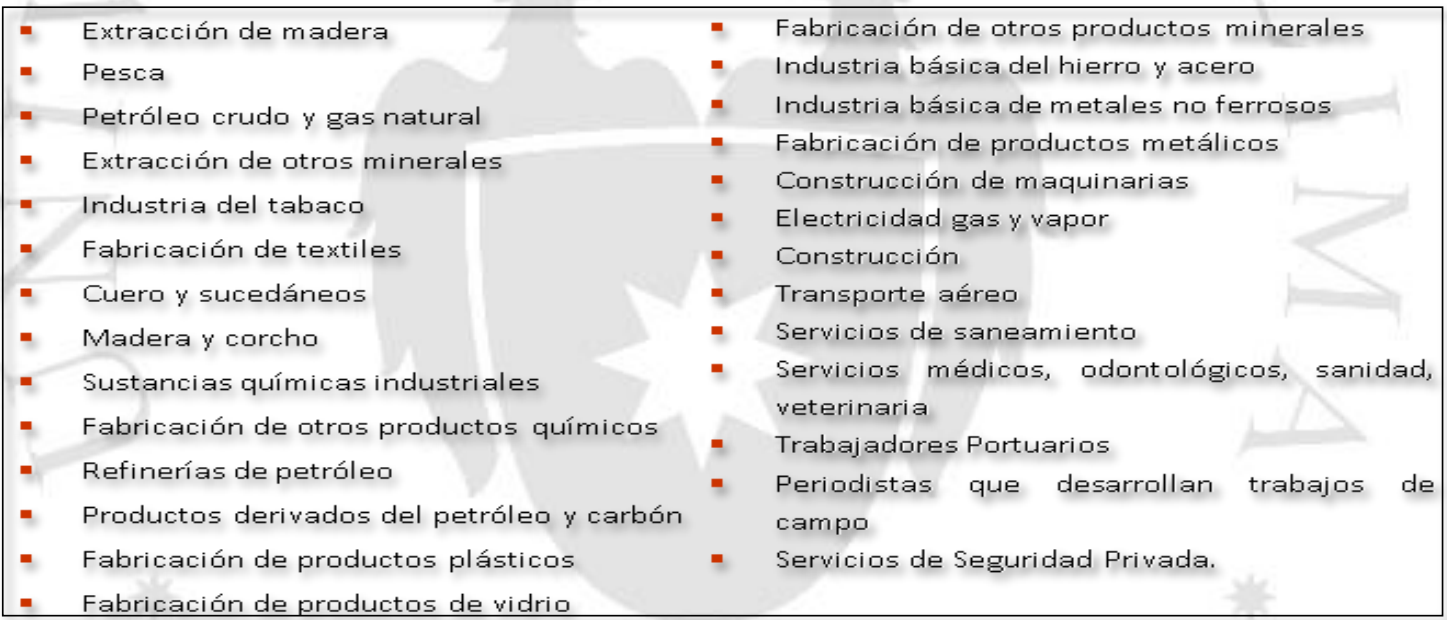

Fuente: Mapfre Perú (2018)

Deben asegurarse obligatoriamente empresas de servicios especiales, cooperativas, contratistas y subcontratistas, así como, toda institución de intermediación o provisión de mano de obra que destaque trabajadores a centros de trabajo que desarrollen actividades de alto riesgo.

De acuerdo a ley el seguro tiene dos coberturas, la cobertura de salud que puede ser brindada por ESSALUD o una EPS y la cobertura de pensiones que puede ser brindada por la ONP o una compañía de seguros. 
Figura 1.5

Coberturas Seguro Complementario de Trabajo de Riesgo

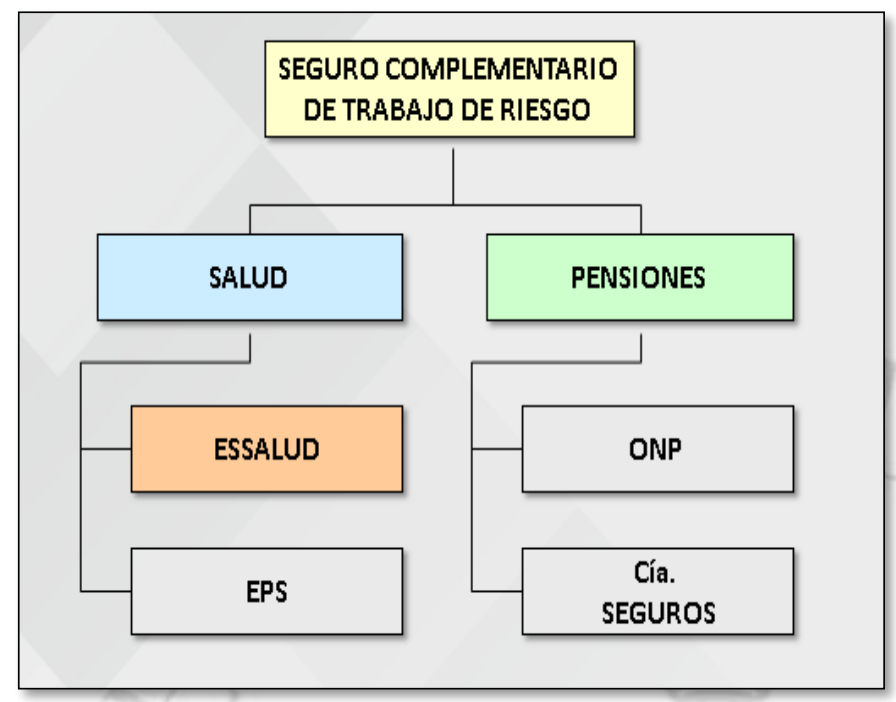

Fuente: Mapfre Perú (2017)

\section{Coberturas de salud}

a) Asistencia y asesoramiento preventivo promocional en salud ocupacional al empleador y a los asegurados.

b) Atención médica, farmacológica, hospitalaria y quirúrgica, cualquiera que fuere el nivel de complejidad, hasta su total recuperación o declaración de invalidez o muerte.

c) Rehabilitación y readaptación laboral al asegurado inválido bajo este seguro.

d) Aparatos de prótesis y ortopédicos necesarios.

\section{Cobertura de pensiones}

a) Pensiones de sobrevivencia 


\section{Tabla 1.1}

Pensión de sobrevivencia

\begin{tabular}{|c|c|c|}
\hline COBERTURA & BENEFICIARIO & BENEFICIO \\
\hline \multirow{6}{*}{$\begin{array}{l}\text { Muerte del } \\
\text { asegurado }\end{array}$} & Cónyuge sin hijo(s) & $\begin{array}{l}\text { Pensión vitalicia igual al } 42 \% \text { de la } \\
\text { Remuneración }\end{array}$ \\
\hline & $\begin{array}{l}\text { Cónyuge con uno o más } \\
\text { hijos }\end{array}$ & $\begin{array}{l}\text { Pensión vitalicia igual al } 35 \% \text { de la } \\
\text { Remuneración }\end{array}$ \\
\hline & Hijo(s) NO huérfano(s) & $\begin{array}{l}14 \% \text { de la Remuneración hasta los } 18 \text { años } \\
\text { o vitalicia si es inválido }\end{array}$ \\
\hline & Hijo huérfano & $\begin{array}{l}42 \% \text { de la Remuneración hasta los } 18 \text { años } \\
\text { o vitalicia si es inválido }\end{array}$ \\
\hline & Hijos huérfanos & $\begin{array}{l}42 \% \text { de la Remuneración + } 14 \% \text { por cada } \\
\text { hijo, en partes iguales, hasta los } 18 \text { años o } \\
\text { vitalicia si es inválido }\end{array}$ \\
\hline & $\begin{array}{l}\text { Padres mayores de } 60 \text { años } \\
\text { y dependientes del causante } \\
\text { o inválidos en más de un } \\
50 \%\end{array}$ & $\begin{array}{l}\text { Hasta } 14 \% \text { de la Remuneración por cada } \\
\text { uno, y sólo si quedara algún remanente }\end{array}$ \\
\hline
\end{tabular}

Fuente: Mapfre Perú (2017)

b) Pensiones de invalidez

Tabla 1.2

Pensión de invalidez

\begin{tabular}{|l|l|l|}
\hline \multicolumn{1}{|c|}{ COBERTURA } & \multicolumn{1}{|c|}{ GRADO DE INVALIDZ } & \multicolumn{1}{c|}{ BENEFICIO } \\
\hline $\begin{array}{l}\text { Invalidez Parcial } \\
\text { Permanente }\end{array}$ & $\begin{array}{l}\text { Igual o superior al 20\% y menor } \\
\text { de } 50 \%\end{array}$ & $\begin{array}{l}\text { Pago único equivalente a 24 } \\
\text { mensualidades en forma proporcional a } \\
\text { la que correspondería a una Invalidez } \\
\text { Total Permanente }\end{array}$ \\
\hline $\begin{array}{l}\text { Invalidez Parcial } \\
\text { Permanente }\end{array}$ & $\begin{array}{l}\text { Igual o superior al 50\% pero } \\
\text { menor al } 66.67 \%\end{array}$ & $\begin{array}{l}\text { Pensión vitalicia igual al 50\% de la } \\
\text { Remuneración }\end{array}$ \\
\hline $\begin{array}{l}\text { Invalidez Total } \\
\text { Permanente }\end{array}$ & Igual o superior al $66.67 \%$ & $\begin{array}{l}\text { Pensión vitalicia igual al 70\% de la } \\
\text { Remuneración }\end{array}$ \\
\hline Gran Invalidez & $\begin{array}{l}\text { Igual o superior al } 66.67 \%, \text { con } \\
\text { incapacidad definitiva para } \\
\text { realizar un trabajo remunerado y } \\
\text { requiere la ayuda indispensable } \\
\text { de otra persona para realizar sus } \\
\text { funciones vitales }\end{array}$ & $\begin{array}{l}\text { Pensión vitalicia igual al 100\% de la } \\
\text { Remuneración }\end{array}$ \\
\hline
\end{tabular}

Fuente: Mapfre Perú (2017)

c) Sepelio

Se reembolsa a la persona (natural o jurídica) que haya sufragado este gasto hasta un monto igual al señalado por la Superintendencia de AFP. 


\subsection{Cuantificación de la industria en volumen de unidades y valor de venta}

\section{Cuantificación del entorno especifico en unidades y valor venta de la industria}

La industria del SCTR facturará el año 2017 S/.656,28 millones, con un crecimiento del $2.9 \%$ con relación al año 2016, en que el mercado no crece, y el 2015 crece por debajo del 5\%, siendo los crecimientos anteriores mayores al 10\%, esto motivado por los factores económicos y políticos que afectaron al país antes descritos en el mercado de seguros. La evolución por productos SCTR Salud y SCTR Pensiones en los últimos años, así como las ventas y participación de Mapfre se muestran en las tablas siguientes:

Tabla 1.3

Crecimiento SCTR SALUD

\begin{tabular}{|l|r|r|r|r|r|}
\hline \multicolumn{1}{|c|}{ SCTR SALUD } \\
\multicolumn{1}{|c|}{ NEGOCIO $/ . \times 1000)$} & \multicolumn{1}{|c|}{ HISTORIAL } \\
\cline { 2 - 6 } & \multicolumn{1}{c|}{2013} & \multicolumn{1}{c|}{2014} & \multicolumn{1}{c|}{ Dic-15 } & \multicolumn{1}{c|}{2016} & \multicolumn{1}{c|}{2017} \\
\hline PNE Mercado. & 216,250 & 236,856 & 255,138 & 255,336 & 255,949 \\
\hline$\%$ Crecimiento mercado & $18 \%$ & $10 \%$ & $7.72 \%$ & $0.08 \%$ & $0.24 \%$ \\
\hline PNE MAPFRE & 45,008 & 53,991 & 61,139 & 67,033 & 76,189 \\
\hline$\%$ Cuota & $20.8 \%$ & $22.8 \%$ & $24.0 \%$ & $26.3 \%$ & $29.8 \%$ \\
\hline$\%$ Crecim. Mapfre & $34.0 \%$ & $20.0 \%$ & $13.2 \%$ & $9.6 \%$ & $13.7 \%$ \\
\hline
\end{tabular}

Fuente: Mapfre Perú (2018)

Tabla 1.4

Crecimiento SCTR PENSIONES

\begin{tabular}{|l|r|r|r|r|r||}
\hline \multicolumn{1}{|c|}{ NCTR PENSIONES } & \multicolumn{1}{c|}{ HISTORIAL } \\
\cline { 2 - 6 }$(\mathrm{s} / . \times 1000)$ & \multicolumn{1}{c|}{2013} & \multicolumn{1}{c|}{2014} & \multicolumn{1}{c|}{2015} & \multicolumn{1}{c|}{2016} & \multicolumn{1}{c|}{2017} \\
\hline PNE Mercado. & 326,844 & 368,764 & 380,158 & 382,263 & 400,333 \\
\hline$\%$ Crecimiento mercado & $21.43 \%$ & $12.83 \%$ & $3.09 \%$ & $0.55 \%$ & $4.73 \%$ \\
\hline PNE MAPFRE & 100,390 & 111,835 & 110,879 & 108,291 & 115,174 \\
\hline$\%$ Cuota & $30.7 \%$ & $30.3 \%$ & $29.2 \%$ & $28.3 \%$ & $28.8 \%$ \\
\hline$\%$ Crecim. Mapfre & $42.9 \%$ & $11.4 \%$ & $-0.9 \%$ & $-2.3 \%$ & $6.4 \%$ \\
\hline \hline
\end{tabular}

Fuente: Mapfre Perú (2018) 
Tabla 1.5

Total crecimiento SCTR PENSIONES+SALUD

\begin{tabular}{|l|r|r|r|r|r||}
\hline \hline \multirow{2}{*}{$\begin{array}{c}\text { NEGOCIO } \\
\text { (s/. X 1000) }\end{array}$} & \multicolumn{1}{c|}{ HISTORIAL } \\
\cline { 2 - 6 } & \multicolumn{1}{c|}{2013} & \multicolumn{1}{c|}{2014} & \multicolumn{1}{c|}{2015} & \multicolumn{1}{c|}{2016} & \multicolumn{1}{c|}{2017} \\
\hline PNE Mercado & 543,094 & 605,620 & 635,296 & 637,599 & 656,282 \\
\hline$\%$ Crecimiento mercado & $20.05 \%$ & $11.51 \%$ & $4.90 \%$ & $0.36 \%$ & $2.93 \%$ \\
\hline PNE MAPFRE & 145,398 & 165,826 & 172,018 & 175,324 & 191,363 \\
\hline$\%$ Cuota & $26.8 \%$ & $27.4 \%$ & $27.1 \%$ & $27.5 \%$ & $29.2 \%$ \\
\hline$\%$ Crecim. Mapfre & $40.1 \%$ & $14.0 \%$ & $3.7 \%$ & $1.9 \%$ & $9.1 \%$ \\
\hline
\end{tabular}

Fuente: Mapfre Perú (2018)

\subsection{Identificación, descripción y participación de mercado de competidores directos.}

Son cuatro compañías de seguros del mercado que comercializan, el SCTR Mapfre se ha mantenido como segundo del mercado, muy cerca del líder Rimac. Se muestra la participación de mercado a diciembre 2017 vs diciembre 2016.

Figura 1.6

Competidores directos SCTR PENSIONES

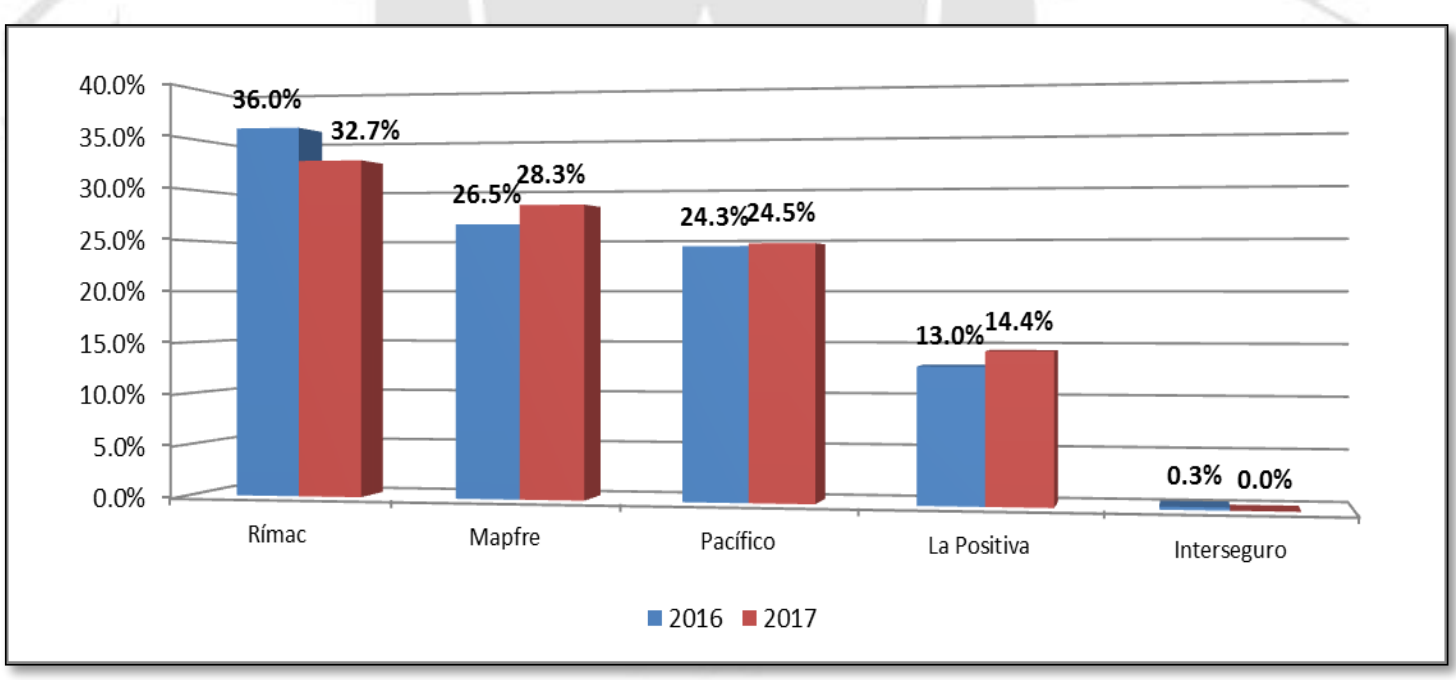

Fuente: Superintendencia de Banca, Seguros y AFP, SBS. (2017) 
Figura 1.7

Competidores directos SCTR SALUD

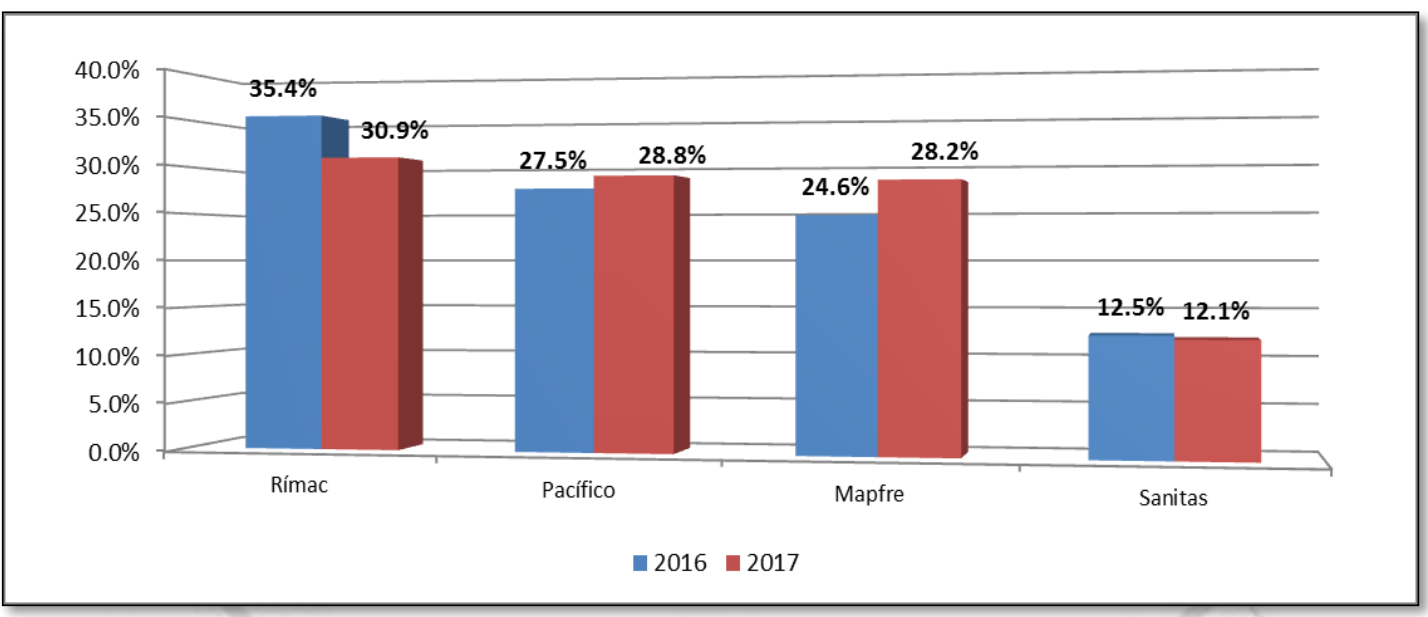

Fuente: Superintendencia de banca, seguros y AFP, SBS. (2017)

\section{- RIMAC}

Fortalezas:

- Solidos acuerdos comerciales con los Brokers más grandes del mercado, con altas comisiones y bonos de mantenimiento y productividad.

- Liderazgo en el mercado asegurador peruano.

- Integración vertical con la clínica internacional perteneciente al mismo grupo económico lo cual le permite acceder a mejores costos médicos.

- Respaldo patrimonial del grupo BRECA, cuyas propias empresas y proveedores le brindan una base sólida de clientes.

- Alianza estratégica con el Banco BBVA Continental del cual son accionistas y es usado como canal de distribución.

Debilidades:

- Enfocado en clientes grandes y corporativos donde se está dando la mayor guerra de precios.

- Concentración geográfica

- Resultado técnico del SCTR pensiones con siniestralidad superior al $100 \%$ durante los últimos años, Siniestralidad a dic. 2016 110\% (Índice de siniestralidad directa según riesgos por empresas de seguro SBS).

- Dependencia del resultado de inversiones para garantizar utilidades debido a la alta siniestralidad. 


\section{- PACIFICO}

Fortalezas:

- Líderes en el sector salud en el país con una participación mayor al 40 \%.

- Integración vertical con su red de clínicas (Clínicas Sanna) lo cual le permite obtener mejores costos de atención.

- Forma parte del grupo Credicorp, además del grupo Romero con empresas tanto en el sector de banca y finanzas y diversos sectores productivos como el consumo masivo.

- Cuentan con el Banco de Crédito como canal de distribución.

- Portafolio de inversiones de bajo riesgo y diversificado

- Solvencia de sus principales accionistas.

Debilidades:

- Concentrado en empresas grandes y corporativas

- Siniestralidad de 115\% a diciembre 2016 en SCTR pensiones (Índice de siniestralidad directa según riesgos por empresas de seguro SBS)

- Alta siniestralidad en Previsionales asociado a la licitación de la POLIZA COLECTIVA.

\section{- POSITIVA}

Fortalezas:

- Fuerte presencia comercial en provincias, siendo la única compañía además de MAPFRE con un foco en Mypes.

- Acuerdos comerciales con medianos corredores con bonos de hasta $25 \%$ por las primas vendidas.

- Es la cuarta compañía aseguradora del mercado domina el mercado de SOAT.

- Altos ingresos financieros

Debilidades:

- Menor solvencia técnica para el SCTR.

- Falta de experiencia ingreso al mercado fuertemente en el 2015 con tasas agresivas.

- Poca experiencia en el sector de salud. 


\section{CAPÍTULO II: DIAGNÓSTICO DEL MARKETING ESTRATÉGICO DE LA EMPRESA}

\subsection{Diagnóstico y análisis de la estrategia genérica:}

Como estrategia genérica, se utilizará una de las 3 estrategias de Michael Porter

Según Porter (2015), en su libro ventaja competitiva: Creación y sostenimiento de un desempeño superior, "el liderazgo en costos consiste en que la organización se propone convertirse en el participante de costos más bajos de su sector". La diferenciación es cuando la empresa intenta distinguirse dentro de su sector en algunos aspectos que son muy valorados por los clientes, escoge una o más atributos que sean percibidos como más importantes y adopta un posicionamiento especial para atender esas necesidades. Por último, el enfoque que se basa en la elección de un estrecho ámbito competitivo dentro del sector la empresa selecciona un segmento o un grupo de segmentos del sector y adapta su estrategia para que atenderlos excluyendo a los demás segmentos, tiene dos variantes que son a) enfoque basado en los costos, los clientes tienen necesidades especiales para poder lograr costos más bajos en el sistemas de producción y de entrega del producto, b) enfoque basado en la diferenciación, aquí se logra explotar las necesidades especiales de los miembros de ciertos segmentos, pues muchas veces los segmentos de empresas no están bien atendidos por los competidores que además tienen otros clientes, así que la empresa puede lograr una ventaja competitiva dedicándose exclusivamente a los segmentos.

Nos basaremos en la estrategia de diferenciación posicionándose como la aseguradora global de confianza, que atiende de manera rápida y especializada a las pequeñas y medianas empresas, además de las empresas corporativas, estando cerca a través de todas sus plataformas de atención (oficinas .web, SI24) y asesorándolas en prevención de riesgos laborales.

Se puede apreciar que dentro del mercado de SCTR Positiva está usando una estrategia de liderazgo en costos sin embargo no tienen la capacidad para brindar el servicio en forma ágil y sobre todo cubrir los siniestros eficientemente.

Rímac y Pacífico utilizan una estrategia de diferenciación dando soluciones 
integrales a todas las necesidades de seguro de la empresa, se apoyan en la fortaleza financiera de sus respectivos grupos económicos.

\subsection{Descripción y análisis de las ventajas competitivas:}

Se realizará el análisis de las cinco fuerzas de Porter como marco conceptual para entender la industria y las fuentes de ventaja competitiva.

Tabla 2.1

Cinco fuerzas de Porter

\begin{tabular}{|c|c|c|}
\hline Fuerza & Descripción & Poder \\
\hline $\begin{array}{c}\text { Rivalidad } \\
\text { existente }\end{array}$ & $\begin{array}{l}\text { - La industria es fragmentada, ya que existen muchas compañías de } \\
\text { seguros. } \\
\text { - Existes empresas en el mercado como Pacífico o Rímac que están } \\
\text { fuertemente posicionados y se están disputando las grandes cuentas } \\
\text { junto con MAPFRE. } \\
\text { - La diferenciación se da por la asesoría en prevención de riesgos } \\
\text { laborales donde MAPFRE inicio y luego fue seguido por Rímac y } \\
\text { Pacífico. } \\
\text { - El esquema de distribución de MAPFRE a nivel internacional implica } \\
\text { la apertura de gran cantidad de oficinas propias distribuidas } \\
\text { geográficamente en las zonas donde opera estrategia que no la tiene } \\
\text { ninguna compañía en el mercado asegurador peruano. }\end{array}$ & tonen \\
\hline $\begin{array}{l}\text { Amenaza de } \\
\text { nuevos } \\
\text { competidores }\end{array}$ & $\begin{array}{l}\text { - Culminado la alianza estratégica entre Positiva seguros y Sanitas EPS } \\
\text { para la comercialización en conjunto del SCTR pensiones y salud } \\
\text { positiva acaba de lanzar su propia EPS en el mes de Julio de } 2017 \text {. } \\
\text { - Protecta comenzará a comercializar el SCTR pensiones en alianza } \\
\text { estratégica con sanitas EPS. }\end{array}$ & $\begin{array}{l}\text { Medio } \\
\text { Alto }\end{array}$ \\
\hline $\begin{array}{c}\text { Amenaza de } \\
\text { disponibilidad de } \\
\text { sustitutos }\end{array}$ & $\begin{array}{l}\text { - La seguridad social a través de ESSALUD y la ONP pueden ofrecer } \\
\text { el seguro SCTR pero en definitiva la cobertura será totalmente } \\
\text { diferente ya que sus tarifas son mayores y no tienen esquemas de } \\
\text { distribución comercial, siendo su cobertura supletoria al SCTR } \\
\text { privado. }\end{array}$ & Medio \\
\hline $\begin{array}{c}\text { Poder de } \\
\text { negociación de } \\
\text { proveedores }\end{array}$ & $\begin{array}{l}\text { - El bróker Marsh cuenta con el } 30 \% \text { de participación de mercado con } \\
\text { una alta concentración en las cuentas corporativas y maneja más del } \\
50 \% \text { de los planes de salud de las EPS, lo convierte en un corredor } \\
\text { con una alta capacidad de negociación. } \\
\text { - Ingresaron al mercado peruano en los últimos tres años Brokers } \\
\text { internacionales del tamaño de Marsh como son: AON, Willis, } \\
\text { Gallaguer y JLT (ya tenía participación en corredores Mariátegui). } \\
\text { Esto ha traído como consecuencia una guerra con Marsh dado que su } \\
\text { posición de dominio no es usual en otros países. } \\
\text { - La alta competencia en el mercado de corredores corporativos ha } \\
\text { traído como consecuencia que las tasas de aporte de abaraten. } \\
\text { - Muchos corredores de seguros medianos han tenido que asociarse con } \\
\text { Brokers de mayor tamaño para poder brindar servicio y proteger sus } \\
\text { cuentas de los grandes corredores tal es el caso de corredores como } \\
\text { Contacto, Italseguros entre otros. }\end{array}$ & Alto \\
\hline
\end{tabular}

(continúa) 


\begin{tabular}{|c|c|c|}
\hline & $\begin{array}{l}\text { - Los corredores de seguros usualmente trabajan con la compañía que } \\
\text { le brinda las mejores comisiones sin embargo buscan eficiencia } \\
\text { operativa y un buen servicio de la compañía de seguros. } \\
\text { - El brokers de seguros pueden influir en la decisión final buscando } \\
\text { muchos de ellos solo la mejor comisión sin pensar en la mejor opción }\end{array}$ & \\
\hline $\begin{array}{c}\text { Poder de } \\
\text { negociación de } \\
\text { clientes }\end{array}$ & $\begin{array}{l}\text { - Dada la ajustada coyuntura económica de los últimos } 3 \text { años y la } \\
\text { competencia entre los grandes corredores la gran mayoría de clientes } \\
\text { corporativos licitaron sus programas de seguros ajustando las primas } \\
\text { del mercado entre } 20 \text { a } 30 \text { por ciento. } \\
\text { - En el caso de los pequeños clientes valoran mucho el acceso, facilidad } \\
\text { de emisión y servicio siendo el poder de las Pymes medio, pues en el } \\
\text { mercado existen muchas compañías de seguros que pueden ofrecer el } \\
\text { seguro SCTR pero no todas tienen un plan dirigido hacia PYMES y } \\
\text { que se adapten a sus requerimientos de rapidez, transparencia y } \\
\text { servicio. }\end{array}$ & $\begin{array}{l}\text { Medio } \\
\text { Alto }\end{array}$ \\
\hline
\end{tabular}

Fuente: Elaboración propia

Como conclusión las principales fuentes de ventaja competitiva son:

- La red de oficinas y distribución a nivel nacional (60 oficinas), que permite a Mapfre llegar de manera directa al cliente final a través de sus redes de venta propias y permite la atención de los corredores medianos y pequeños a nivel nacional, además de la atención específica para Grandes Cuentas y Cuentas Institucionales.

- Los sistemas, que le permite una operativa eficiente en la emisión, cobranza y atención de siniestros, permitiendo llegar a segmentos como las Pymes que tiene alto costo de transacción para corredores y compañías del mercado.

- El Servicio de Prevención de Riesgos Laborales, que le ha permitido posicionarse como expertos en prevención, fidelizando a los clientes y bajando la siniestralidad, este mismo servicio lo tiene Mapfre desde que nace en 1933 en España y lo exporto a los diferentes países donde trabaja los Riesgos del Trabajo (SCTR en el Perú), tales como Argentina y Colombia. Las otras compañías del mercado son seguidoras de Mapfre en este servicio.

\subsection{Descripción y análisis de la estrategia de marketing corporativo:}

Las estrategias de marketing que usa Mapfre a nivel corporativo vienen a ser estrategias en búsqueda de aumentar la participación de mercado y captar nuevas cuentas buscando aumentar su presencia tanto en canales como en volumen de facturación:

Algunas estrategias utilizadas son: 
- Penetración de mercado: Según Domínguez y Muñoz (2013) definen la penetración del mercado como el conjunto de acciones que usa una empresa para poder aumentar su participación en los segmentos que opera. Dentro del SCTR Mapfre busca penetrar el mercado de clientes corporativos, ofreciendo una propuesta de valor diferenciada, buscando identificarse por la eficacia y su experiencia en el mercado, buscando de esta forma aumentar su participación en clientes corporativos, nicho el cual está muy fraccionado pero aún con condiciones de crecimiento.

- Desarrollo de mercado: Según Domínguez y Muñoz (2013), definen la estrategia de desarrollo de mercado como la capacidad de una organización en desarrollar y llegar a segmentos de mercado antes no explotados. Mapfre dentro del SCTR como objetivo busca desarrollar nuevas cuentas y aumentar su participación de mercado desarrollando nuevas oficinas en provincias fuera de Lima de tal forma que se tenga más llegada a las personas de igual forma busca ampliar el segmento de clientes pequeños y masivos (Pymes) este un segmento con mucho atractivo ya que no ha sido muy explotado por la dificultad de llegada a los mismos por eso Mapfre busca aumentar su presencia principalmente ampliando el canal Digital y través de su gran red de oficinas y de ventas lo cual le permite estar más cerca a los mismos y atender sus diferentes necesidades.

\subsection{Descripción y análisis de las estrategias competitivas de marketing:}

Según Kotler y Keller (2016), "existen diferentes estrategias competitivas según cada empresa las mismas pueden ser Retadoras, Líderes, Seguidoras y Especialista en nichos" (p. 337). Dentro del mercado de SCTR para la estrategia competitiva, se eligió las estrategias de Philip Kotler usando la estrategia de "especialista en nichos", debido a que se cuenta con la participación de mercado necesaria y los recursos para poder atender las necesidades de sus diferentes clientes gracias al gran número de agencias y una propuesta de valor enfocada específicamente para la atención de los mismos. Dentro del mismo el líder de mercado es RIMAC usando una estrategia incremento de la participación de mercado, el retador sería Positiva con una estrategia específicamente de precios bajos pues con una política de primas por debajo del precio de mercado, así como de comisiones altas para los Brokers intentan ganar participación de mercado. El seguidor sería PACÍFICO ellos utilizan una estrategia de adaptación e intentan con los recursos que cuentan intentar llegar a todos los segmentos posibles. El especialista en nichos seria 
Mapfre ya que apunta a crecer por medio de las medianas y pequeñas empresas sin descuidar el segmento corporativo, esto gracias a su gran cantidad de canales de ventas.

\subsection{Descripción de los grupos objetivos}

Según Kotler y Roberto (2009), el público objetivo en general puede definirse como el grupo de personas al que desea dirigirse una determinada organización en un momento concreto de tal forma que se puedan orientar acciones concretas hacia las mismas. En este caso usaremos la segmentación para observar a los grupos objetivos en los cuales Mapfre en el SCTR los tiene definidos de la siguiente forma:

\section{SEGMENTACIÓN:}

Mapfre segmenta el mercado basado principalmente en dos variables: Actividad y Monto de Primas.

Tabla 2.2

Segmentación de clientes SCTR por monto de primas anuales

\begin{tabular}{|c|c|}
\hline CATEGORÍA & PRIMA (S/.) \\
\hline PRINCIPALES & 500M a mas \\
\hline GRANDES & 200M a 500M \\
\hline MEDIANOS & $100 \mathrm{M}$ a 200M \\
\hline PEQUEÑOS & 20M a $100 \mathrm{M}$ \\
\hline MASIVO & hasta 20M \\
\hline
\end{tabular}

Fuente: Mapfre Perú (2018) 
Tabla 2.3

Segmentación de clientes SCTR Matriz Actividad vs. Monto de Primas

\begin{tabular}{|l|c|c|c|c|c|}
\hline & PRINCIPALES & GRANDES & MEDIANAS & PEQUEÑOS & MASIVOS \\
\hline MINERIA & $\mathrm{X}$ & $\mathrm{X}$ & $\mathrm{X}$ & & \\
\hline CONSTRUCCION & $\mathrm{X}$ & $\mathrm{X}$ & $\mathrm{X}$ & $\mathrm{X}$ & $\mathrm{X}$ \\
\hline METALMECANICA & & $\mathrm{X}$ & $\mathrm{X}$ & $\mathrm{X}$ & $\mathrm{X}$ \\
\hline TRANSPORTE & & $\mathrm{X}$ & $\mathrm{X}$ & $\mathrm{X}$ & $\mathrm{X}$ \\
\hline PUERTOSY LOGIST. & $\mathrm{X}$ & $\mathrm{X}$ & $\mathrm{X}$ & & \\
\hline TRANSF. DE METALES & $\mathrm{X}$ & & & & \\
\hline ELECTRICIDAD & & & $\mathrm{X}$ & & \\
\hline GAS PETROLEO & & $\mathrm{X}$ & & & \\
\hline PESCA & & $\mathrm{X}$ & $\mathrm{X}$ & & \\
\hline SALUD & $\mathrm{X}$ & & $\mathrm{X}$ & & \\
\hline MANUFACTURERAS & & & $\mathrm{X}$ & $\mathrm{X}$ & $\mathrm{X}$ \\
\hline SERVICIOS & & & $\mathrm{X}$ & $\mathrm{X}$ & $\mathrm{X}$ \\
\hline
\end{tabular}

Fuente: Mapfre Perú (2018)

Los canales de venta son agrupados de la siguiente forma:

Tabla 2.4

Agrupación de los canales de venta

\section{GRANDES CUENTAS \\ RED PLAZA Y RED SCTR \\ CANAL DIGITAL \\ LICITACIONES \\ CORREDORES LIMA Y PROVINCIAS}

Fuente: Mapfre Perú (2018)

Basados en esta segmentación cada uno de los Canales de Venta con que cuenta la compañía se especializa para atenderlos de la siguiente manera: 
Tabla 2.5

Canales de Venta

\begin{tabular}{|c|c|c|c|c|c|}
\hline & Principales & Grandes & Medianos & Pequeños & Masivo \\
\hline \multicolumn{6}{|c|}{ GRANDES CUENTAS } \\
\hline \multicolumn{6}{|c|}{ Sub Central LIMA } \\
\hline \multicolumn{6}{|c|}{ CUENTAS INSTITUCIONALES } \\
\hline \multicolumn{6}{|c|}{ Subcentral NORTE } \\
\hline \multicolumn{6}{|c|}{ Subcentral SUR } \\
\hline \multicolumn{6}{|c|}{ Subcentral Centro LIMA } \\
\hline \multicolumn{6}{|c|}{ Subcentral Centro PROVINCIAS } \\
\hline \multicolumn{6}{|c|}{ RED PLAZA } \\
\hline \multicolumn{6}{|l|}{ RED SCTR } \\
\hline \multicolumn{6}{|c|}{ AMARILLO: Menor participación } \\
\hline
\end{tabular}

Fuente: Mapfre Perú (2018)

Los clientes grandes y principales, están concentrados en los Canales Grandes Cuentas, y Cuentas Institucionales.

La Subcentral Lima, atiende algunos clientes grandes, pero principalmente clientes medianos, pequeños y masivos (Pymes).

Los clientes pequeños y masivos, se concentran en el resto de subcentrales, así como en las redes propias.

\subsection{Descripción del posicionamiento de la empresa}

Según Maqueda y Llaguno (1995) hay dos objetivos para posicionar a una empresa de servicio y estos van dirigidos hacia las expectativas del cliente y hacia la competencia los mismos son ¿Cómo perciben el servicio? ¿Con que rasgos y cualidades distintivas se desea diferenciar? (p.89).

Mapfre busca posicionarse como la aseguradora global de confianza.

Dentro del SCTR, busca diferenciarse por los siguientes atributos:

- Cercanía, por distribución geográfica (60 oficinas) con especialización de los canales por tipo de cliente.

- Facilidad Operativa, facilidad de emisión de pólizas y resolución eficaz de siniestros. 
- Servicio de Prevención de Riesgos Laborales, con lo cual diferencia el producto y da un valor añadido, fideliza a los clientes y baja la siniestralidad, asesorando y apoyando a los clientes en la gestión de la prevención de riesgos, haciendo inspecciones a los centros de trabajo, brindando cursos, diplomados en prevención, señalización, entre otros servicios.

\subsection{Descripción de la creación del Brand Equity}

Según Kotler y Roberto (2009) en su libro Marketing Social, el Brand Equity es el valor que tiene la marca en el tiempo, todo esto gracias a los esfuerzos de la compañía por crear, mantener, mejorar y proteger sus marcas.

La marca Mapfre ha recibido los siguientes reconocimientos durante el año 2018, siendo una de las compañías de seguros más grandes del mundo.

Top Emphatic Brands: MAPFRE es la cuarta marca más empática del IBEX 35 según el estudio Top Emphatic Brands 2018, realizado por la consultora SUMMA. El informe analiza el uso de la inteligencia emocional y la habilidad de escuchar y entender de verdad a los públicos, entre otras variables.

Brand Finance Insurance 100: MAPFRE es la $31^{\text {a }}$ compañía aseguradora más valiosa del mundo según el ranking que elabora la consultora internacional Brand Finance, en el que analiza las 100 aseguradoras más valiosas, los factores que ayudan a que las marcas sean más reconocidas y los valores que mejor fidelizan.

Brand Finance: MAPFRE es la novena marca más valiosa de España y líder en la industria aseguradora en 2018, registradando un crecimiento de la marca MAPFRE de un $17 \%$ hasta los 2.794 millones de euros evalúa la facturación, los beneficios y el impacto emocional.

Se puede decir que el valor que tiene Mapfre para sus clientes según datos cuánticos y reconocimientos de diferentes empresas, es alto, en el SCTR se ve reflejado en su mayoría de casos con relaciones de largo plazo con clientes los cuales son fidelizados y reconocen a Mapfre por sus atributos diferenciales. Se puede concluir que a lo largo del tiempo el Grupo Mapfre y Mapfre Perú dentro del SCTR mantiene un valor en el tiempo que se ve reflejado en sus renovaciones de pólizas, clientes contentos y con relaciones de largo plazo, Mapfre busca siempre ser la aseguradora global de confianza y eso está reflejado en cada una de sus unidades de negocio. 


\section{CAPITULO III: DESCRIPCIÓN DEL CASO O PROBLEMA}

\subsection{Marketing Operativo}

Mapfre Perú busca aumentar su participación en todos sus canales tomando como componente principal del marketing mix a su plaza, ya que es gracias a ella que se logra llegar a diferentes segmentos de mercado aumentando su presencia de marca y de tal forma estando presente en todos los canales en los cuales opera.

Se decidió explicar las 7ps del servicio como estrategia para entender mejor el negocio:

\subsubsection{Descripción del servicio básico o principal}

El servicio que brinda Mapfre con el SCTR, tiene dos coberturas una por salud permitiendo a los trabajadores atenderse en clínicas privadas en caso de accidente de trabajo y la cobertura de pensiones en caso el trabajador quede invalido o fallezca como consecuencia de un siniestro, brindando un servicio de prevención de riesgos que asesora a las empresas para evitar accidentes. El producto será vendido a través de vía web, agencias, corredores de seguros y agentes propios (red plaza y red SCTR).

\subsubsection{Descripción de la Flor de servicios complementarios}

La flor de servicios es un diagrama donde se muestran los servicios complementarios que puede ofrecer una organización y que agregan valor a los clientes. Según Hoffman (2011), se desarrollará las ocho variables de la flor de servicios, es decir representan los servicios comentarios que se deberían ofrecer y cuáles podrían ser útiles para mejorar el servicio. Dentro del SCTR comercializado por Mapfre se encuentran los siguientes atributos por pétalo: 
Figura 3.1

Flor de servicios

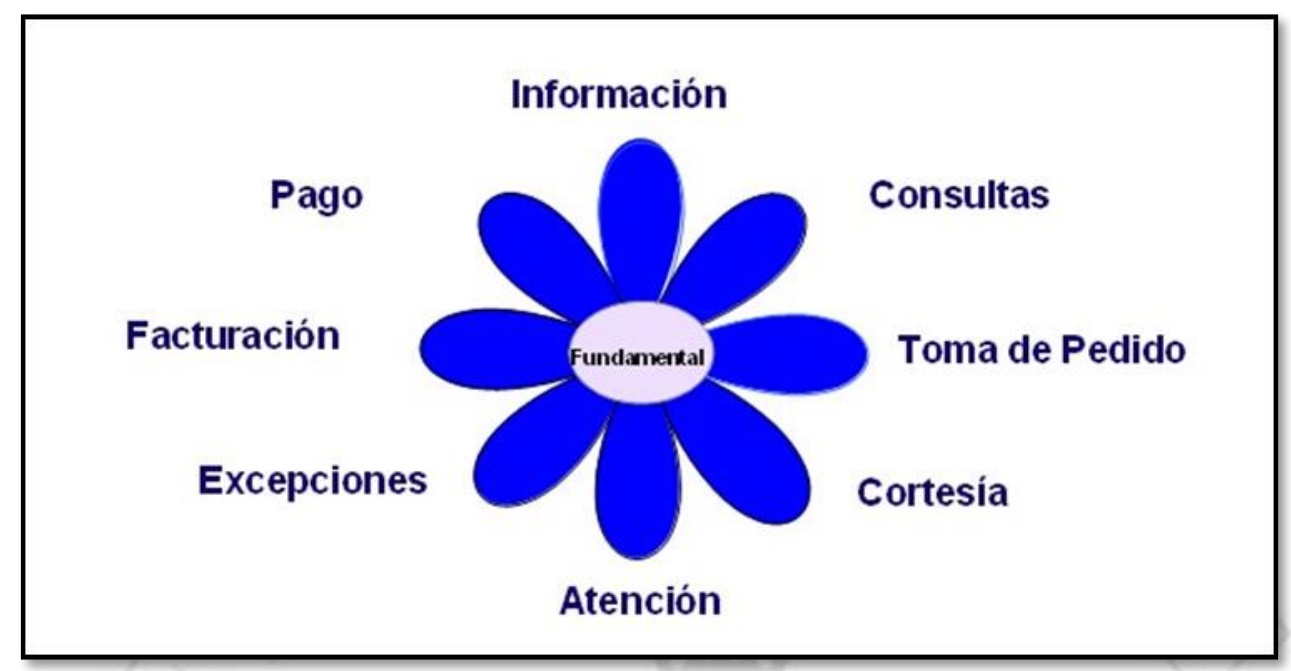

Fuente: Elaboración propia.

\section{a) Información}

La información que utiliza Mapfre para sus clientes sobre sus diferentes productos es de forma sencilla y amigable de tal forma que el cliente entienda los beneficios de cada seguro, se busca emplear un lenguaje donde los términos técnicos del seguro puedan ser entendidos. Dentro de SCTR se cuenta con el portal web donde se brinda información sobre el seguro, coberturas, condiciones, exclusiones entre otras, de igual manera en cada agencia Mapfre se brinda la información exacta sobre el seguro. Se tiene folletería resumida con las coberturas y principales características del seguro.

\section{b) Consultas}

En cuanto a las consultas son básicamente para resolver inquietudes y dudas de los clientes para eso se cuenta con el SI24 de Mapfre y la total atención por parte del personal encargado de atención al cliente. Existe un protocolo para derivar las llamadas telefónicas y para atención en oficinas de tal manera que el cliente pueda ver satisfechas sus dudas.

\section{c) Toma de pedido}

La toma del pedido se realiza a través de los diferentes canales de venta. Esta también en proceso de implementación con la red de agentes el proyecto Mydream a través del cual los mismos pueden cotizar, emitir y cobrar a través de tablets. Además se cuenta con la OIM (oficina Internet Mapfre), desde la cual los clientes y corredores pueden interactuar con la compañía. 


\section{d) Cortesía}

Mapfre tiene protocolos hacia los canales y se hacen mediciones de calidad de servicio, cuenta además con merchandising y folletería necesario que se le entrega a cada cliente cuando ingresan a una oficina o cuando vienen por una consulta. Para Mapfre el capital humano y las personas son lo primordial por lo cual todos son tratados con el debido respeto y cortesía que se merecen.

\section{e) Atención}

La atención dentro de las oficinas es rápida y eficaz gracias al sistema operativo con el que cuenta la empresa lo cual le permite emitir pólizas de manera rápida. Además se cuenta con la OIM. La atención frente a un siniestro es de igual forma muy rápida con solo una llamada al SI24 se puede llegar al punto de siniestro en muy poco tiempo ya que se cuenta con convenios en todo el Perú con las principales clínicas además de peritos motorizados.

\section{f) Facturación}

La facturación se da multiplicando la planilla mensual por la tasa de aporte. Se tiene una prima mínima neta de S/.200 (S/.100 por cada producto)

\section{g) Pago}

Los pagos se realizan por depósitos o transferencias bancarias, al emitir la póliza se genera un recibo con número el cual se encuentra interconectado con los principales bancos. Además hacia fines del 2018 los agentes de las redes propias podrán cobrar con tarjeta de crédito a través de sus tablets.

\subsubsection{Precio}

La estrategia de precio de nuevo producto es de valor percibido, ya que los clientes reconocen la calidad del servicio es por eso que deciden elegir a Mapfre como la empresa con la cual trabajar.

Según Nagle y Holden (2009), los cercos de precios pueden ser físico o no, los físicos se refieren a los atractivos por los cuales se obtiene una ventaja y los no físicos se refiere a las restricciones, membresías, tiempo de uso y restricciones (p. 98). 
El precio es determinado por la siguiente forma:

Tabla 3.1

Medición del precio promedio

\begin{tabular}{|l|c|c|c|c|c|c|c|c|c|}
\hline & FRECLENC Costo medio & Prima de Ries 20 & sueldo medidtasa de ries & Gastos Adm Comisiones & Utilidad & tasa comercial \\
\hline SCTR PENSIONES & $0.07 \%$ & 140,000 & 98 & 1250 & $0.653 \%$ & $20 \%$ & $15 \%$ & $12 \%$ & $1.23 \%$ \\
\hline SCTR SALUD & $9 \%$ & 900 & 81 & 1250 & $0.540 \%$ & $20 \%$ & $15 \%$ & $12 \%$ & $1.02 \%$ \\
\hline \hline
\end{tabular}

Fuente: Mapfre Perú (2017)

Se toma S/ 1,250.00 soles como salario medio mensual.

- La frecuencia ser refiere al número de accidentados por cada 100 trabajadores

- El costo medio es el costo del siniestro de acuerdo a la experiencia en Mapfre

- La prima de riesgo se obtiene multiplicando la frecuencia por el costo medio.

- La tasa de riesgo se obtiene dividiendo la prima de riesgo entre el sueldo medio.

- En caso de la tasa comercial se le agrega los gastos administrativos las comisiones y la utilidad esperada.

Las tasas que se aplican dependerán del sector productivo, el número de trabajadores, el sueldo medio y las medidas de prevención de riesgos con que cuenta la empresa.

\subsubsection{Distribución y canal.}

A nivel nacional el grupo Mapfre cuenta con una red de oficinas siendo esta la más grande de todo el Perú a nivel seguros (más de 60 oficinas). Esto le permite estar más cerca a sus clientes en el caso de las Pymes la cercanía de agentes y puntos de apoyo con los que se cuenta son puntos claves para desarrollar la propuesta de valor y tener mayor llegada a ellos.

El éxito de Mapfre a nivel mundial que comenzó en su casa Matriz en España fue su red de distribución de oficinas, en España en los pueblos más pequeños se puede encontrar una oficina de Mapfre siendo la primera aseguradora de este país, este esquema se ha replicado en el Perú, el desarrollo de las oficinas ha demandado 20 años de trabajo aperturándose actualmente un promedio de 3 a 4 oficinas por año, esta estrategia es totalmente diferente usada por las demás compañías de seguros. 
A diferencia de lo que se puede encontrar en el mercado nacional, en cada oficina de Mapfre se puede llevar a cabo todo el proceso del seguro desde la cotización, emisión, cobros y pagos de siniestros.

Cada oficina cuenta con un director de oficina y por lo menos un gestor comercial, los gestores comerciales pueden ser de corredores o de redes propias.

Las oficinas además cuentan con empleados de atención al cliente (EAC) los cuales se encargan de la atención de consultas, la emisión de pólizas el cobro y el pago de siniestros.

Los EAC tienen un plan de carrera desde Junior hasta Master, sus funciones están en función de su categoría.

En las oficinas se atienden a los Brokers asignados de acuerdo a distribución geográfica o a solicitud de ellos, además se atiende a los clientes en forma directa.

Se han hecho acuerdos con corredores el año 2017 en las oficinas principales de capitales de departamento, escogiéndose 2 o 3 corredores con capacidad de producción. En total se han hecho acuerdos para el plan Pyme con 94 corredores a nivel nacional con una producción estimada de S/. 19 millones de soles. $25 \%$ más que el año anterior.

Se cuenta con 571 agentes plaza y 103 agentes de la red específica de SCTR a diciembre del 2017, estos se encuentran distribuidos a nivel nacional.

Cabe resaltar que si bien no corresponde a este producto Mapfre cuenta con redes propias para los productos de decesos, salud, hogar y vida.

Las oficinas están distribuidas por todo el Perú de la siguiente forma: 
Figura 3.2

Agencias a nivel nacional

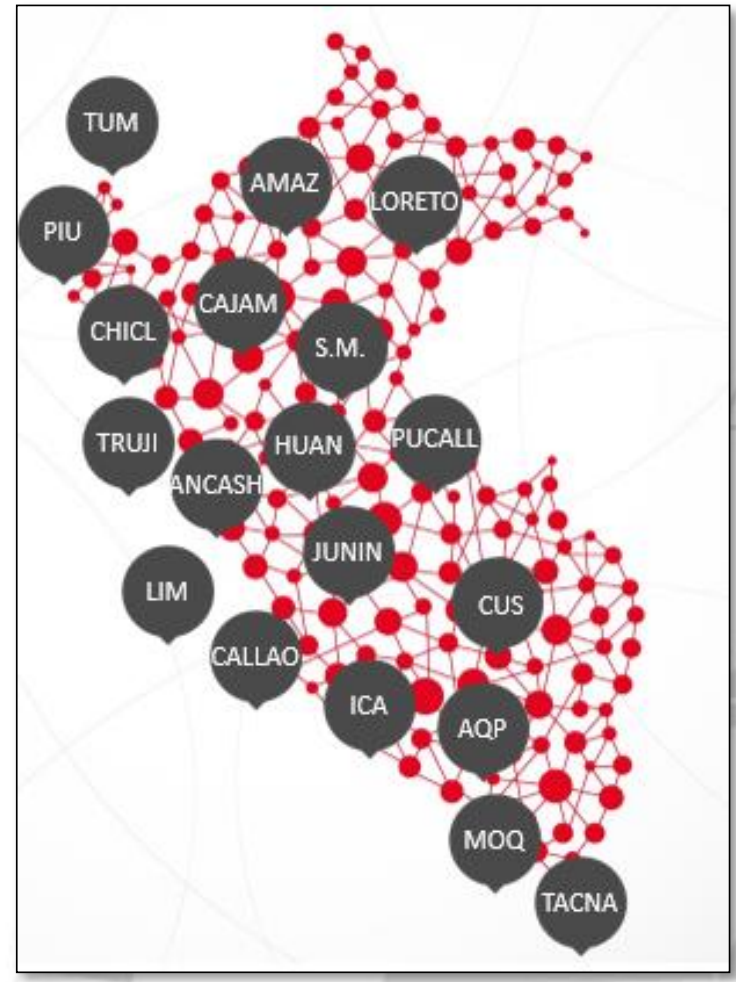

Fuente: Mapfre Perú (2018)

Figura 3.3

Oficinas en el Perú

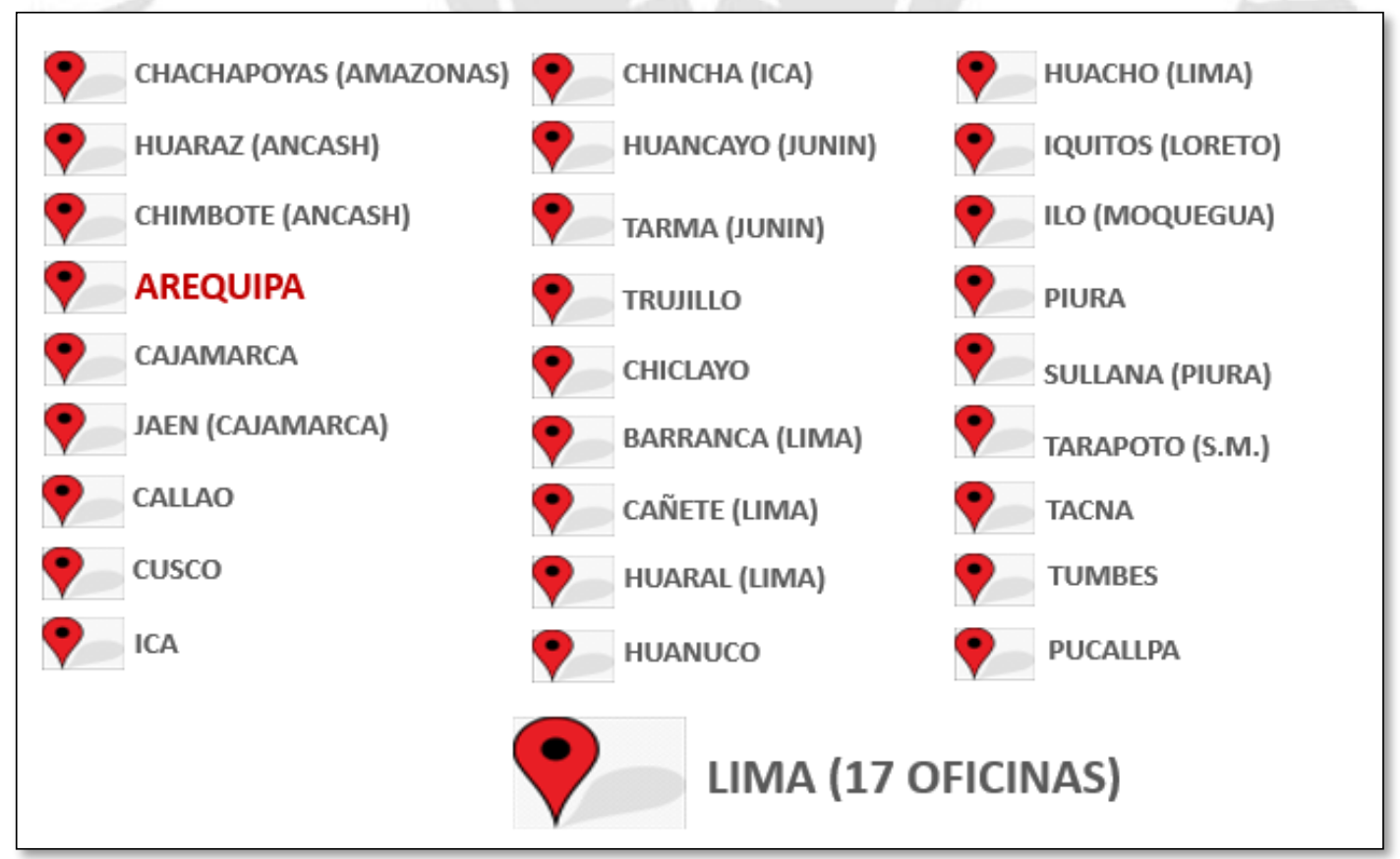

Fuente: Mapfre Perú (2018) 
Mapfre usa una distribución geográfica distribuyendo oficinas a lo largo del país para así tener mayor contacto y llegada a sus clientes.

En lo que se refiere a agencias dentro de Lima o provincia el cliente llegará por su propia cuenta a la agencia o ya se por la publicidad dentro del punto de venta, activaciones BTL, elementos publicitarios, elementos exteriores y elementos interiores.

\subsubsection{Comunicaciones integradas}

Mapfre no hace uso de publicidad masiva dentro de ese segmento ya que no se necesita. Como estrategia de comunicación integrada se hará uso de del SI24 con el cual el cliente puede comunicarse las 24 horas con Mapfre además del uso de redes sociales, pues son los medios más usados y que no se requieren de una gran inversión. Según Lovelock (2011), existe un impacto de internet en las comunicaciones actuales a medida que el internet gane terreno como canal.

Las actividades de comunicaciones estarán dadas por las siguientes actividades en redes sociales

- Facebook

- Instagram

- Twitter

Los elementos gráficos a usar serán website, fan page en Facebook los volantes y afiches que serán distribuidores dentro de puntos estratégicos. Se usará además Merchandising en cada agencia después de realizada una operación. 
Figura 3.4

Portada de Facebook

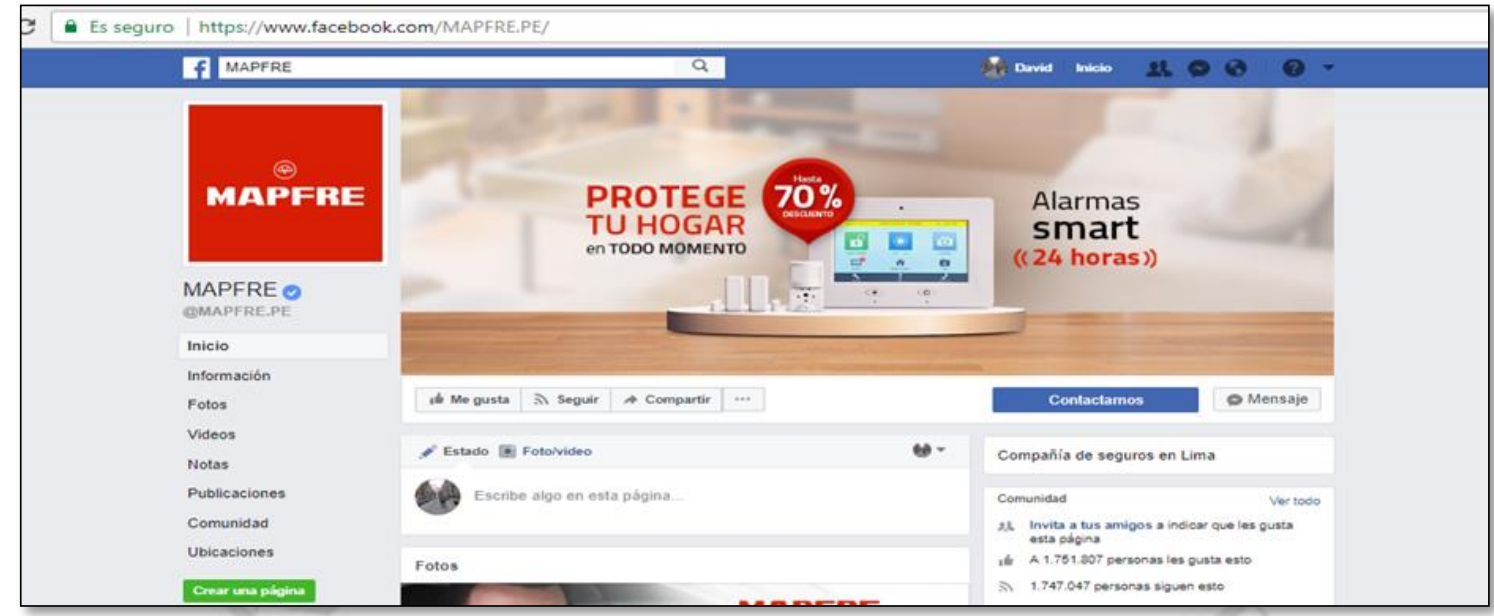

Fuente: Elaboración propia

\subsubsection{Evidencia física}

Las oficinas cuentan con publicidad BTL fuera de ellas, todas tienen el logotipo de Mapfre de forma resaltante de tal forma que pueda llamar la atención. Dentro de ellas el ambiente es muy ordenado, con varios puestos de atención al cliente y de gestores comerciales de tal forma que se puedan concretar ventas y atender necesidades de cualquier tipo de cliente.

Figura 3.5

Oficina con publicidad BTL

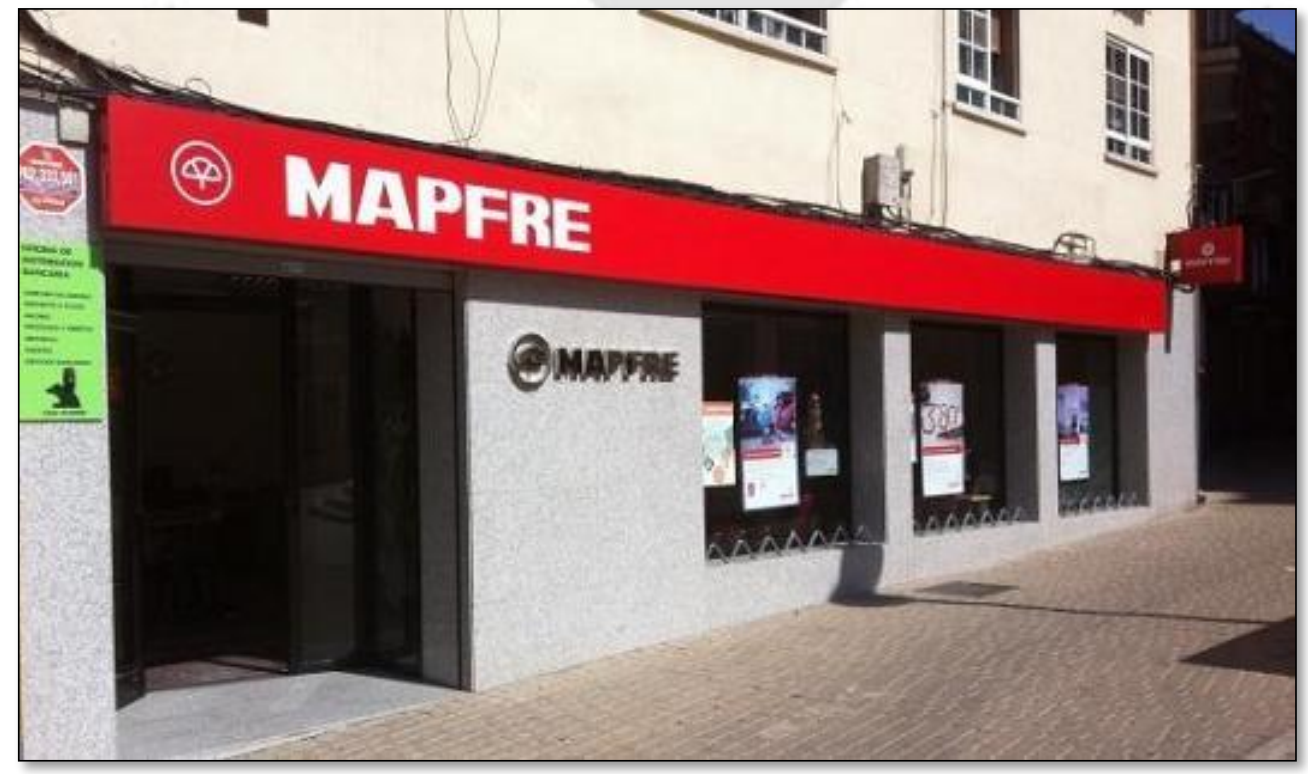

Fuente: Elaboración propia 


\subsubsection{Procesos}

Tabla 3.2

Flujograma del servicio básico o principal

\begin{tabular}{|c|c|}
\hline 1er Contacto & $\begin{array}{l}\text { - Cliente ingresa a la tienda por necesidad de adquirir un } \\
\text { seguro de inmediato es atendido por un ejecutivo de } \\
\text { atención al cliente el cual la ayuda con el tramite que desee } \\
\text { realizar. }\end{array}$ \\
\hline 2do Contacto & $\begin{array}{l}\text { - Los ejecutivos de ventas informan y asesoran cual es el } \\
\text { mejor seguro que necesitan, a cual califican de tal manera } \\
\text { que los clientes puedan estar orientados. En caso de } \\
\text { emisión inmediata el proceso es muy breve y se realiza en } \\
\text { plataforma. } \\
\text { Decisión de compra }\end{array}$ \\
\hline & $\begin{array}{l}\text { El cliente se decide por uno de los seguros a utilizar. } \\
\text { - Se concentra la compra con el pago de la prima minima } \\
\text { con el medio de pago que el cliente desee. }\end{array}$ \\
\hline
\end{tabular}

Fuente: Elaboración propia

Se específica estas 3 etapas de modelo de compra en el canal el cual es una oficina o agencias Mapfre que comercializan el SCTR.

Según Lovelook y Wirtz (2015) existen 3 etapas previas a la compra de un servicio:

- Etapa previa a la compra: Búsqueda de información: aclarar necesidades, evaluación de alternativas, Discutir opciones con el personal de servicio. Al ser el SCTR un producto obligatorio para determinados sectores productivos, las empresas buscan información a través de la asesoría de corredores y agentes en su gran mayoría quienes se encargan de dar la información de coberturas, exclusiones y beneficios.

- Etapa del encuentro de servicio: Solicitud del servicio al proveedor elegido, encuentro del servicio. En esta etapa Mapfre busca ser muy ágil en las cotizaciones y emisión de pólizas y documentos, a través de sus diferentes canales de ventas y de la OIM.

- Etapa posterior al encuentro: Evaluación del desempeño del servicio, a través de la atención de siniestros y la emisión mensual de documentos y constancias de aseguramiento, necesarias para el cliente ante una visita del Ministerio de Trabajo. (p. 36) 


\subsubsection{Personas}

La estructura de Mapfre se divide en 5 áreas fundamentales: Técnica, Comercial, Operaciones, Financiera y medio además de Tecnología e información y procesos. Explicados en el punto 2.

\subsubsection{Dimensiones de calidad del servicio:}

Según Lovelook y Wirtz (2015), existen diferentes dimensiones para medir la calidad del servicio:

a) Tangibles (apariencia de los elementos físicos, equipo, personal y material de comunicación): Entro los elementos físicos están las oficinas, todas están diseñadas bajo un formato similar estandarizado según se detalló en el punto 5 (evidencias físicas), el personal cuenta con uniformes y el material tanto de promoción como las pólizas y documentos que se entregan al cliente son estandarizados.

b) Confiabilidad (capacidad para desempeñar el servicio prometido con seguridad y precisión): Mapfre busca ser la aseguradora global de confianza, para esto se ha implementado un sistema de calidad que se detalla más adelante en el punto Sistema de medición de Calidad del Servicio de Mapfre, que entre otros aspectos busca que qué el servicio se brinde confiablemente.

c) Respuesta (prontitud y utilidad): Se cuenta con un grado de respuesta rápida y de prontitud cuya calidad también se mide, estableciéndose estándares de tiempo de respuesta para los principales procesos (ver Sistema de medición de Calidad del Servicio de Mapfre) esto a través de las diversas plataformas de intercomunicación con el cliente, siendo la principal el SI24 el cual trabaja las 24 horas, además de las plataformas WEB, oficinas y agentes.

d) Certidumbre (Pericia, cortesía, credibilidad y seguridad): La empresa cuenta con un alto grado de fiabilidad y credibilidad, busca cumplir con sus compromisos. La integridad, entendida como exigencia de actuación ética, socialmente responsable y generadora de compromisos a largo plazo, se incluye entre los valores esenciales de MAPFRE y forma parte de los Principios Institucionales, Empresariales y Organizativos aprobados formalmente por el Consejo de Administración de su empresa matriz.

La cortesía y el trato con el cliente también se controlan y miden en los indicadores de calidad, así mismo en las mediciones de cliente anónimo tanto para llamada 
telefónica como para atención en oficinas, según se detalla más adelante en el punto Sistema de medición de Calidad del Servicio de Mapfre y en Medición de calidad mediante Cliente Anónimo Telefónico y Presencial.

e) Empatía (fácil acceso, buena comunicación y comprensión del cliente): Mapfre viene trabajando desde hace varios años una estrategia de Onnicanalidad, que busca que toda la comunicación e interacción con el cliente sea coherente y la misma por los distintos canales que el cliente quiera usar para interactuar con la compañía, ya sea el SI24, la WEB, las oficinas, los agentes. Para esto se ha desplegado una importante inversión en sistemas para que la información del cliente esté disponible, este trabajo todavía se esta realizando para contar con la información del cliente, para conocerlo mejor y darle un mejor servicio, los desarrollos de sistemas son proyectos multianuales que se van terminado por etapas, por ejemplo a fines de este año los agentes de la red propia a través de sus tablets podrán tener mayor acceso a mayor cantidad de procesos con información del cliente, en el caso de SCTR podrán suscribir riesgos sencillos, emitir pólizas y constancias así como hacer la cobranza ya sea por banco o directamente con tarjeta de crédito.

Por otro lado se viene trabajando en adecuar las pólizas e información hacia el cliente para colocarlos en un lenguaje más entendible con menos términos técnicos propios de la actividad aseguradora que el grueso de los clientes no entiende.

\subsubsection{Sistema de medición de Calidad del Servicio de Mapfre:}

Mapfre establece como Misión: actuar como un equipo que trabaja para avanzar constantemente en el servicio y para desarrollar la mejor relación con clientes, distribuidores, proveedores, accionistas y la Sociedad.

Por lo anterior como una herramienta fundamental de la gestión de la empresa se cuenta con un sistema de medición de calidad del servicio, donde se miden estándares de cumplimiento para todas las unidades del grupo mostrados en el organigrama, incluidos el área comercial, unidades de negocios, tecnología de la información y procesos, financiera y medios, legal, recursos humanos, auditoria y todos los principales procesos.

Es un sistema y metodología que nació en Perú hace 15 años y va mejorándose año a año. La casa matriz estableció el sistema peruano como base para los diferentes países en que opera. 
Se establecen notas en función de estándares para los principales procesos de la compañía, por ejemplo, para el proceso: aprobación de cartas garantía para atención de clínicas, se estableció que la misma se debe dar antes de las 3 horas, con lo cual en las mediciones del sistema se asigna una nota de 10 si se hace en menos de 3 horas, nota de 5 , si se demora entre 3 a 5 horas y nota de cero si se demora más de 5 horas.

Todos los Funcionarios de la compañía tienen una meta de Calidad como parte de sus bonos anuales, además toda persona que tenga dentro de su remuneración bonos anuales, la meta de calidad de su unidad es parte de su bono. Cada año se establece una meta de Calidad para la compañía, de alcanzar la misma la compañía paga un súper bono a los Funcionarios.

Las mediciones se realizan cada trimestre y en caso de obtener algún puntaje bajo o deterioro en algún proceso se tienen que establecer planes de acción. Los mismos se hacen públicos en las reuniones trimestrales del llamado G40 (grupo de 40 cabezas de la compañía).

Se hace llegar a cada Gerente o Director de la unidad involucrada en la medición las observaciones realizadas por los diversos grupos encuestados y se tiene la obligación de establecer un plan de actuación en caso de notas bajas en determinado grupo o proceso, así mismo se escucha la opinión de clientes internos, agentes y clientes externos para la mejora continua. Todas las encuestas son realizadas por una empresa la cual es contratada externamente y los datos duros del sistema son extraídos directamente de los reportes del mismo.

Los puntajes de calidad del servicio son los siguientes:

Tabla 3.3

Puntajes de calidad del servicio

\begin{tabular}{|c|c|c|c|c|}
\hline MALO & REGULAR & BUENO & MUY BUENC & EXCELENTE \\
\hline $0-3.9$ & $4-5.9$ & $6-7.9$ & $8-8.9$ & $9-10.0$ \\
\hline
\end{tabular}

Fuente: Mapfre Perú (2018)

Para el caso específico del SCTR se miden los siguientes procesos:

- Emisión

- Siniestros

- Actividades Comerciales 
- Atención al cliente.

Estas cuatro variables son medidas mediante datos duros del sistema (data real registrada) y percepción de Clientes Externos, Clientes Internos y Red Agencial, cada proceso y cada unidad tiene sus propios medidores, para el caso de SCTR, se muestran algunos ejemplos sin ser una lista total de todas las mediciones:

\section{Datos del sistema (tiempos de respuesta registrados en cada proceso)}

Ejemplos:

- Tiempo entre que la clínica solicita la carta de garantía y la misma es aprobada (siniestros).

- Tiempo entre que se emite una póliza en oficina y es levantado el control técnico (emisión).

- Tiempo de absolución de reclamos (Atención al cliente).

Clientes internos: Encuestas a los Empleados de atención a los clientes, empleados administrativos.

Ejemplos:

- Percepción del tiempo de emisión y levantamiento de controles técnicos (emisión).

- Percepción del producto frente a la competencia (actividades comerciales).

\section{Red agencial: Encuestas a los agentes propios y corredores.}

Ejemplos:

- Percepción del tiempo de tramitación de constancias (Emisión).

- Percepción del tiempo de aprobación de cartas garantía (siniestros).

- Percepción de la Oficina Internet Mapfre (OIM) frente a la competencia.

- Percepción del producto frente a la competencia (actividades comerciales).

\section{Clientes Externos: Encuestas a los clientes}

Ejemplos:

- Encuesta a Asistentas Sociales de clientes sobre la calidad de atención en siniestros de SCTR pensión.

- Encuesta a clientes a los que se ha brindado el Servicio de Prevención. 
Los puntajes obtenidos en las mediciones del 2018 para la unidad de negocio del SCTR se muestran en el siguiente cuadro:

Tabla 3.4

Unidad del negocio del SCTR

\begin{tabular}{|l|c|c|c|}
\hline & \multicolumn{2}{c|}{ RIESGOS DEL TRABAJO } & \multirow{2}{*}{ PROMEDIO } \\
\cline { 2 - 4 } & 1 TRI & 2 TRI & \\
\hline ACTIVIDADES COMERCIALES & 8.29 & 8.55 & 8.42 \\
\hline ATENCION AL CLIENTE & 8.5 & 9.74 & 9.12 \\
\hline EMISION & 8.43 & 8.7 & 8.57 \\
\hline SINIESTROS & 8.87 & 9 & 8.93 \\
\hline CONSOLIDADO & $\mathbf{8 . 5 2}$ & $\mathbf{9}$ & $\mathbf{8 . 7 6}$ \\
\hline
\end{tabular}

Fuente Mapfre Perú (2018)

Se puede ver que la medición de calidad del año 2018 fue la esperada logrando obtener un puntaje muy alto lo cual refleja el compromiso del personal con las metas de la empresa.

\section{- Medición de calidad mediante Cliente Anónimo Telefónico y Presencial}

Además como parte del sistema de calidad se hacen mediciones de cliente anónimo tanto telefónico como presencial y que buscan la calidad del servicio que sirve para reforzar los valores MAPFRE: Vocación de Servicio, Equipo comprometido e Innovación para el liderazgo, asociados a las Estrategias competitivas MAPFRE: orientación al cliente, compromiso e innovación.

Estos valores y estrategias MAPFRE están relacionadas a principios básicos de servicio exigidos por la casa Matriz:

Para el cliente anónimo telefónico se resumen en los siguientes pasos:

CONTESTA Antes de las tres timbradas

SALUDA

MAPFRE buenos/días/tardes/noches le atiende/ le saluda "Nombre"

(Si conoce) Conoce la necesidad del cliente, brinda la

ATIENDE/ RESUELVE solución y ofrece los servicios y/o beneficios MAPFRE.

(No conoce) Conoce la necesidad del cliente, informa que no tienes el alcance y deriva correctamente al área 
respectiva indicando: persona que llamó, sus datos de contacto y motivo de llamada.

DESPÍDETE

De forma cordial y que genere continuidad en la relación con MAPFRE.

Para el cliente anónimo presencial se resume en los siguientes pasos:

SALUDA

Buenos/días/tardes/noches mi nombre es "XXXX " en que lo(a) podemos ayudar.

CONECTA

Solicita nombre de la persona, DNI/RUC y motivo de visita.

(Si conoce) Conoce la necesidad del cliente, brinda la solución y ofrece los servicios y/o beneficios MAPFRE.

(No conoce) Conoce la necesidad del cliente, informa

ATIENDE / RESUELVE que no tienes el alcance y deriva correctamente al Jefe Directo: Director de oficina, Agente o Supervisor, quien resolverá el caso, indicando los datos de la persona y motivo de visita.

DESPÍDETE De forma cordial y que genere continuidad en la relación con MAPFRE. 


\section{Valoraciones}

Tabla 3.5

Tabla de Valoración de la atención al cliente

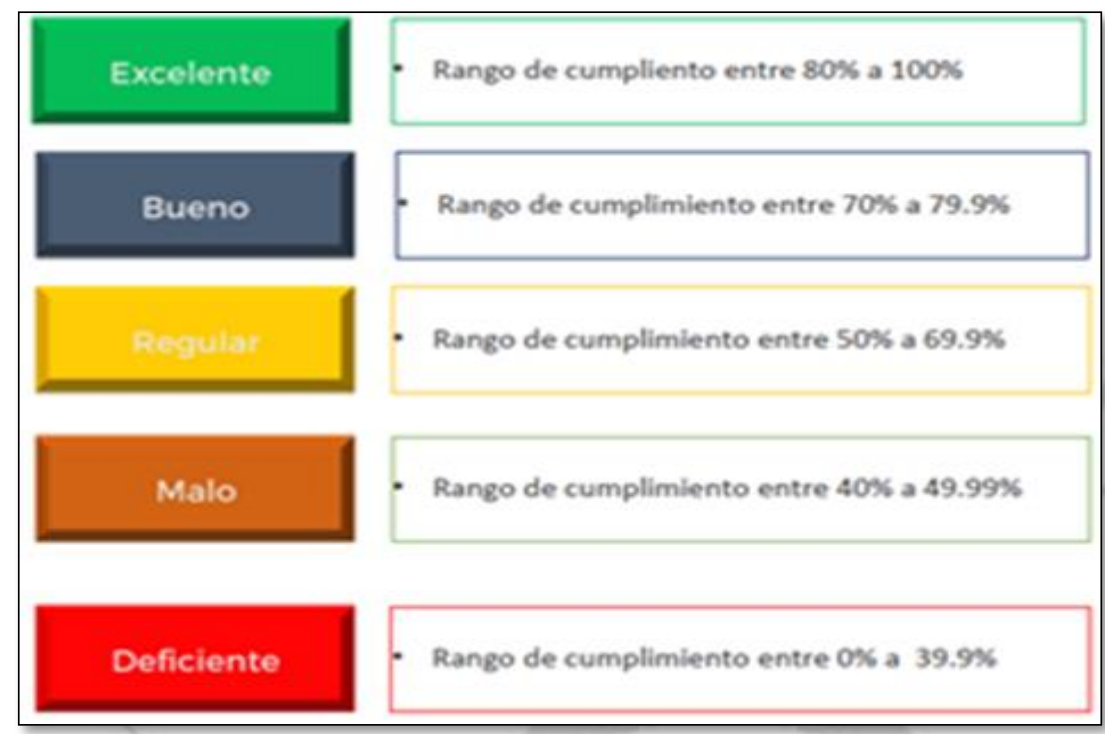

Fuente Mapfre Perú (2018)

Las puntuaciones obtenidas también se entregan a los Directores y Gerentes involucrados.

Se capacita al personal y se realizan campañas, la medición de cliente anónimo se hace en todas las unidades y a todo nivel en la compañía.

\subsubsection{Modelo de las Brechas}

Lovelock y Wirtz (2015) menciona las 6 brechas elaboradas por Zeithaml, Parasuraman y Berry dentro de los servicios, las primeras 5 conducen a la última, las mismas son:

- La brecha del conocimiento: Mapfre cuenta con un estándar de capacitación para los agentes comerciales propios, hasta que cumplan un año de contratados los agentes son subvencionados económicamente costando hasta el $40 \%$ de la producción y venta que realizan, durante este periodo es probable que ofrezcan al cliente mayores beneficios a los realmente contratados, sin embargo las encuestas y porcentaje de retención de clientes después de unos meses de contratado son enviados a sus jefes inmediatos para determinar la permanencia o no de la gente dentro de la compañía, habiendo una rotación muy alta dentro de los primeros seis meses de contratado el 
personal. Por otro lado, se procura que todos los empleados se apoyen en la tecnología y en los sistemas que tienen omnicanalidad y por tanto actúen según los estándares de la empresa. Mapfre a nivel internacional trabaja muy fuerte para que sus servicios sean estandarizados por todos los canales, sin embargo, se observa que los intermediarios especialmente los agentes propios nuevos y los corredores con poca producción en la compañía, ofrecen beneficios equivocados, o más allá de los contractuales, esto se da especialmente en el segmento de Pymes, mas no en el corporativo que está altamente controlado.

- La brecha de la política: Esta brecha ha sido ampliamente desarrollada con los grandes clientes, midiéndose su satisfacción y teniendo a Mapfre en este producto el porcentaje más alto de renovación de pólizas, superior al $90 \%$, mediante el servicio de prevención de riesgos laborales, ayudando a los clientes a la implementación de sus programas y políticas en esta materia, sin embargo estos servicios han sido difíciles de llevar a las Pymes, por su alto costo de implementación y de llegar uno a uno, en estos momentos se procura llegar a las mismas mediante medios digitales. Mapfre trabaja con todos sus empleados un proceso de estandarización de servicios hacia el cliente para asegurar la confiabilidad y consistencia de sus servicios, en un proceso de mejora continua en el cual se toma en consideración, el feedback de clientes externos, intermediarios y clientes internos. El principal problema que se observa está en la rotación de trabajadores de las áreas comerciales que obliga a la empresa a un alto gasto en capacitación y entrenamiento para lograr los estándares objetivos.

- La brecha de la entrega: Esta brecha está ampliamente cubierta según opinión de los clientes, los agentes propios y los corredores, Mapfre es la empresa más eficiente en la emisión de pólizas y entrega de documentación, el SCTR es un producto de obligación legal y Mapfre ayuda a sus clientes a tener los requisitos, exigidos por el ministerio de trabajo en mejores tiempos con relación al mercado. Esto está respaldado por los sistemas y tecnología puestos al servicio del cliente. La ventaja que tiene Mapfre en este sentido es que similares productos son comercializados en países como Colombia, Argentina, Portugal o España con un knock how que no lo tienen otras compañías del espacio Nacional y que desarrollar los sistemas necesarios implican un alto costo inicial, que Mapfre ya lo cubrió en otros países. 
- De las entrevistas realizadas, se detectó que en los últimos meses ha habido muchos problemas por caídas del sistema y de la OIM, esto se debe a que los servidores se encuentran en Miami, para solucionar esta caída que se ha dado en toda Sudamérica ha sido necesario que la casa matriz alquile mayor capacidad de hardware al proveedor que brinda este servicio.

- La brecha de las comunicaciones: Mapfre a nivel local y a nivel global no es la compañía más barata, ni la que paga mayores comisiones a los intermediarios, sin embargo, procura ser la compañía global de confianza, vale decir que cumple con sus compromisos a las emisiones de la póliza, es así que es la compañía que menos reclamos tiene a nivel nacional, de las cuatro más grandes, procurando establecer expectativas realistas en los clientes. De lo observado Mapfre cuenta con un servicio post-venta muy efectivo en pólizas corporativas, logrando una alta fidelización a pesar de no haber contratado dichos clientes el Plan de Salud de la EPS con Mapfre, la principal brecha se da en clientes Pymes a los cuales no se puede llegar uno a uno, es por eso que se está desarrollando sistemas a través de los cuales dichos clientes se puedan auto-atender por medios digitales, tal es así que el servicio de prevención acaba de lanzar cursos de formación en Seguridad y Salud en el trabajo de tal manera que los clientes puedan cumplir con los requisitos legales de la norma de seguridad y salud en el trabajo apoyados por la compañía.

- La brecha de la percepción: Mapfre procura que ante la atención de algún siniestro el empleador este enterado de la evolución y atención médica de su trabajador. Mapfre trabaja para que los tiempos de descanso médico ante un accidente de trabajo sean lo más corto posible es así que la rehabilitación de los accidentados se está trasladando a los centros médicos propios de tal manera de tener mayor control sobre el siniestro, esto es ampliamente apreciado por los clientes pues no requieren contratar personal de reemplazo y sus índices estadísticos de accidentabilidad mejoran. Además según se vio las cartas de garantía son aprobadas en su gran mayoría antes de tres horas. Lo cual es muy valorado por los clientes pues el mercado nacional puede demorar varios días en aprobar las mismas. Además, los sistemas informáticos permiten una emisión y cobranza muy ágil.

- La brecha de la calidad del servicio: Si bien es cierto la compañía cumple en su gran mayoría con las 5 brechas antes mencionadas, se concluye que hay oportunidades de mejora especialmente en los clientes pequeños como las Pymes, 
dichas brechas dado el alto costo que representa llegar a dichos clientes en comparación con las Primas que pagan, solamente pueden ser superadas mediante medios digitales.

\subsection{Evolución de la venta por canales, descripción del problema:}

A continuación se presenta la evolución de la venta por canales y segmentos a los cuales están dirigidos y un análisis de la situación actual:

Figura 3.6

Cuadro venta por canales

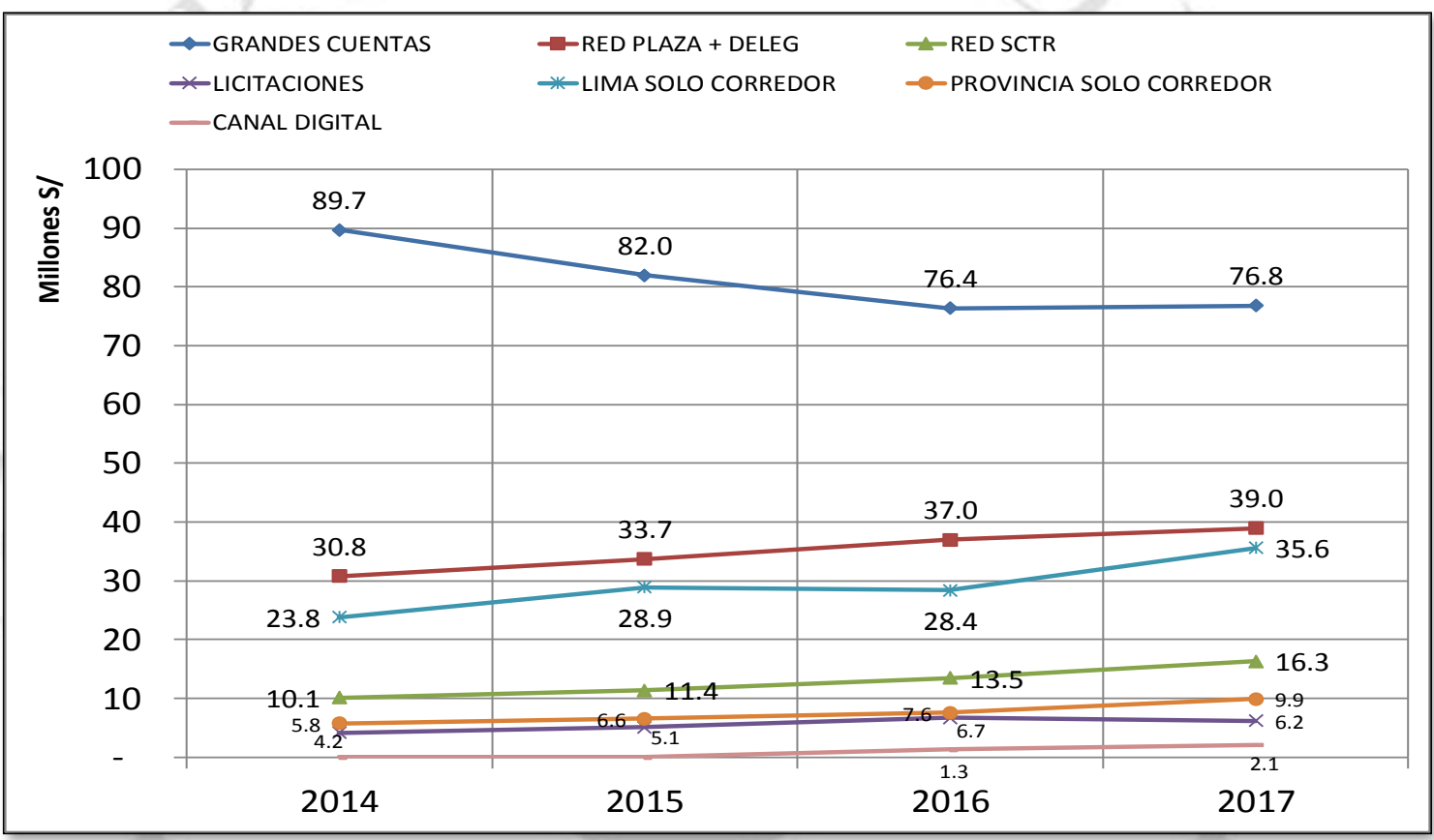

Fuente Mapfre Perú (2018)

Tabla 3.6

Evolución de distribución porcentual por canal de ventas

\begin{tabular}{|l|c|c|c|c|}
\hline SCTR PENSIONES+SALUD & $\mathbf{2 0 1 4}$ & $\mathbf{2 0 1 5}$ & $\mathbf{2 0 1 6}$ & $\mathbf{2 0 1 7}$ \\
\hline GRANDES CUENTAS & $53.9 \%$ & $48.3 \%$ & $44.2 \%$ & $40.9 \%$ \\
\hline RED PLAZA & $18.5 \%$ & $19.9 \%$ & $21.4 \%$ & $20.7 \%$ \\
\hline RED SCTR & $6.1 \%$ & $6.7 \%$ & $7.8 \%$ & $8.7 \%$ \\
\hline LICITACIONES & $2.5 \%$ & $3.0 \%$ & $3.9 \%$ & $3.3 \%$ \\
\hline LIMA SOLO CORREDOR & $14.3 \%$ & $17.0 \%$ & $16.5 \%$ & $18.9 \%$ \\
\hline PROVINCIA SOLO CORREDOR & $3.5 \%$ & $3.9 \%$ & $4.4 \%$ & $5.3 \%$ \\
\hline CANAL DIGITAL & $0.0 \%$ & $0.0 \%$ & $0.8 \%$ & $1.1 \%$ \\
\hline
\end{tabular}

Fuente Mapfre Perú (2018) 


\subsubsection{Análisis situación actual de la venta por canales:}

\section{$\underline{\text { Grandes Cuentas }}$}

- En este canal se concentran las compañías Principales y Grandes, así como los grandes corredores del mercado como: Marsh, AON, JLT, Willis, Contacto, Gallaguer.

- Las ventas han bajado consistentemente en los últimos años, pasando de facturar S/. 89.7 Millones el 2014 a S/76.8 Millones el 2017 (-15\%) y pasando de ser el 53.9\% de las ventas al $40.9 \%$ en el mismo periodo.

- Esto se da producto de guerra de precios y mayor competencia en este segmento donde se concentran Rimac y Pacífico, e ingresa Positiva agresivamente desde el 2015, además de la paralización de obras grandes de infraestructura y menor inversión por inestabilidad política.

- Dentro de los principales clientes de Mapfre se encuentran constructoras como: Grupo Graña y Montero, JJC; mineras como: Cerro Verde, Volcan, Glencore, Pan American Silver, Chinalco; puertos y logística como: DP Word, Grupo A\&H, Tisur, entre otros.

- Mapfre tiene la desventaja de no ser fuerte en Planes de Salud de la EPS, que en muchas ocasiones se vende en paquete con el SCTR.

- El servicio de prevención y la fidelización lograda en este segmento es muy fuerte, siendo sus renovaciones superiores al 90\%, difícilmente Mapfre pierde clientes en este segmento.

Al ser las grandes empresas del mercado donde se da la mayor batalla comercial y donde están concentrados Rimac y Pacifico, Mapfre aposto por diversificar el crecimiento a través de la red de oficinas a nivel nacional y las redes propias, las cuales se dirigen a clientes medianos, pequeños y masivos.

\section{Redes Propias: Red SCTR, Red Plaza}

- $\quad$ En Redes propias, la Red Plaza (que vende todos los productos de Mapfre con 571 agentes a diciembre 2017) y la Red SCTR (especializada en venta de SCTR con 103 agentes a diciembre de 2017) pasaron de facturar S/.40.9Millones el 2014 a S/.55.3 Millones el 2017 (crecimiento de 35\%), pasando de ser el 24.6\% de las ventas al $29.4 \%$ en el mismo periodo. 
- Los clientes de las redes propias son básicamente Pequeñas y Medianas empresas a nivel nacional, segmento en franco crecimiento.

- Este segmento del mercado es muy poco explotado por la competencia, dado el alto costo que implica llegar con asesoría personalizada a pequeños clientes.

- Mapfre por estrategia corporativa a nivel internacional se dedica a la formación de redes propias, en el Perú la única compañía de la competencia que formo una red específica de SCTR fue Pacífico con 90 agentes.

- Se está ingresando a segmentos del mercado donde no llegan el resto de compañías tales como: talleres de carpintería en el distrito de Villa el Salvador, Metal mecánica en el cono Norte de Lima.

- Se está ingresando también en clúster productivos en provincias tales como contratistas en Talara o Industria del cuero en Trujillo.

- Se están desarrollando herramientas informáticas para que los agentes a finales del 2018 puedan emitir y cobrar directamente desde sus Tablets.

- El problema se da por el alto costo de llegar uno a uno con servicio post venta en prevención de riesgos.

\section{$\underline{\text { Red Digital }}$}

- Para consolidar la red digital, esta estuvo dirigida inicialmente a los productos de Personas (no de empresas), tales como: Autos, Soat, Salud, Decesos, Vida.

- La red Digital de Mapfre a diciembre de 2017 está conformada por 199 agentes que venden todos los productos de la compañía, recién empiezan a comercializar SCTR el 2016, siendo el 2017 el 1.1\% de las ventas con S/2.1 Millones, habiendo una oportunidad de crecimiento en este canal.

\section{$\underline{\text { Licitaciones }}$}

- El canal de Licitaciones es otro en el que se concentran clientes Grandes y Principales del Estado, siendo el principal cliente de Mapfre por número de trabajadores Essalud (60mil trabajadores), además de Petroperú, SIMA, Ministerios como Transportes y Agricultura entre otros.

- El canal de licitaciones facturo el 2017 S/6.2 Millones representando el 3.3\% de las ventas, sin embargo al ser las mismas empresas que se licitan anualmente, es un segmento que ha dejado de ser rentable por la guerra de tarifas. Es así que algunos clientes de este segmento están dando pérdida de utilidades 
- En este canal hay una oportunidad de crecimiento en Licitaciones especialmente en Municipalidades y Gobiernos Regionales, sin embargo el armado de los expedientes está todavía centralizado en Lima y no se concursa por falta de capacidad operativa y conocimiento en agencias, dado que las licitaciones deben de cumplir con toda la parte documental para ser presentadas.

\section{Corredores Lima y Provincia:}

- También se aposto por el crecimiento en corredores medianos de Lima y Provincias atendidos a través de la red de oficinas nacional, desde el 2016 estos han pasado a estar a cargo de una sola Gerencia.

- Los corredores son atendidos en red de oficinas a nivel nacional donde se les soluciona todos sus requerimientos

- $\quad$ Los corredores de provincia pasaron de facturar S/.5.5 Millones el 2014 a S/.9.9 Millones el 2017 (crecimiento de 80\%), y los de Lima de S/.23.8 Millones a S/.35.6 Millones (crecimiento de 50\%) en el mismo periodo, en forma conjunta representan el $24.2 \%$ de las ventas (vs. $17.8 \%$ el 2014).

- Estos corredores pueden tener algún cliente grande pero se concentran en medianos y pequeños.

- En este segmento Mapfre paga menores comisiones que su competencia, por lo que la estrategia de crecimiento se da por el servicio, ayudando al corredor en la fidelización de sus clientes y solucionando la operativa de emisión, constancias de aseguramiento y facturación a través de la misma oficina que lo atiende o a través de la OIM.

- Se ha buscado seleccionar corredores estratégicos por cada oficina a los cuales se les ofrece planes específicos de incentivos por crecimiento y rentabilidad, estos corredores están fidelizados con Mapfre y al ser pocos en cada oficina, permite una focalización en el servicio.

\subsubsection{Estrategias por canal}

Según Munuera Alemán y Rodríguez Escudero (2010), la matriz de Mackinsey sirve para ubicar a los canales según el atractivo de mercado y según la posición competitiva en la cual se encuentra. Dentro de los canales del SCTR esta matriz permite saber si se debe si 
se debe invertir más en un canal y saber la posición estratégica actual en la cual se encuentra el mismo basándonos en la problemática explicada:

Tabla 3.7

Estrategias por canal

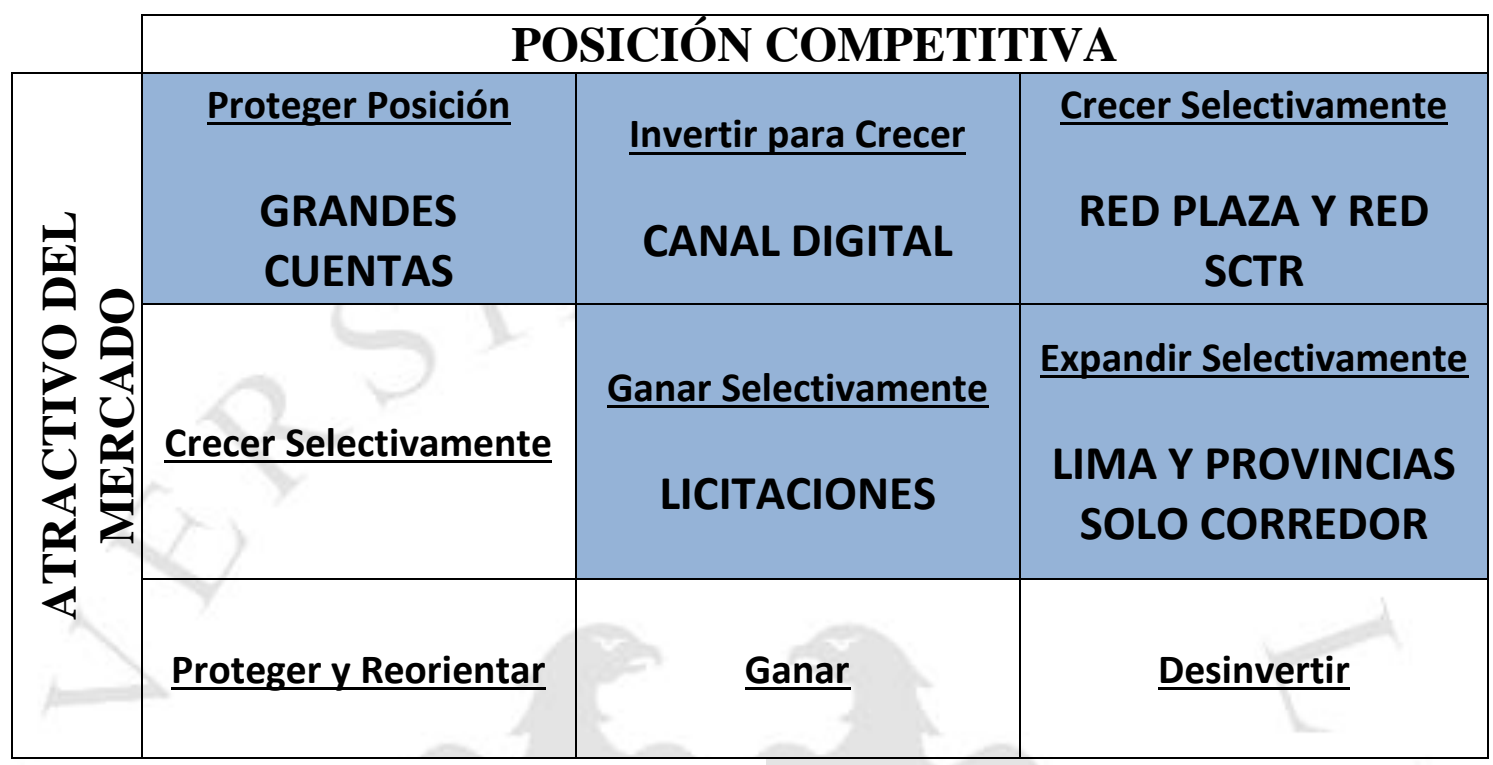

Fuente: F. R. David, F. David y Hernán D'Borneville. (2017)

Elaboración propia

Dada la problemática del mercado de SCTR se decidió por utilizar estrategias competitivas de crecimiento para cada canal de ventas individualmente y en algunos estrategias defensivas todo esto basándonos en su registro histórico de ventas y la situación actual en la cual se encuentra cada canal, todo esto con el fin de mantener su participación de mercado e intentar aumentar su presencia en otros canales.

\section{a. Grandes Cuentas}

- Al ser las grandes empresas del mercado donde se da la mayor batalla comercial y donde están concentradas las empresas de la competencia como Rímac y Pacifico, y al ser los crecimientos pequeños según se analizó se debe dar protección a la Participación de Mercado (Dirección de Marketing, Kotler Keller 2016).

- Para Mapfre este segmento es el corazón o negocio central del SCTR con una participación cercana al 30\% en empresas corporativas.

- La calidad del Servicio es vital en este segmento, lo cual permite tener al cliente fidelizado.

- Se decidió utilizar estrategias defensivas como la de defensa móvil, en esta se busca extender el dominio de nuevos territorios a través de la ampliación o diversificación 
de mercado, buscando de esta forma mantener y cosechar las grandes cuentas y de igual forma usar la estrategia de Diversificación de mercado buscando aumentar su participación de mercado, captando medianas y pequeñas empresas en las que muchas empresas de la competencia no pueden competir todo esto se logra gracias a la gran cantidad de oficinas y agencias, estas cuentas de igual forma representan una gran parte las ventas y se espera retomen el crecimiento.

- También se recomienda la estrategia de Defensa Preventiva, atacando clientes objetivo de la competencia, es así que en el mes de julio 2018, Mapfre le gano a Pacífico su cliente más grande Southern Perú, con una facturación superior a los S/11Millones de soles (1.75puntos del mercado).

- Además Mapfre debe anticipar futuras inversiones en infraestructura, energía, petróleo, minería entre otros para captar nuevos clientes en este segmento desde antes que empiecen operaciones.

\section{b. Red Plaza y Red SCTR}

- Se decidió utilizar la estrategia de Desarrollo de Nuevos Mercados buscando llegar a nuevos mercados como pequeñas y medianas empresas Pymes, que actualmente no cuentan con el producto, dado el alto grado de informalidad en el país (70\%).

- Además las redes propias llegan a provincias y clúster económicos, aprovechando de esta forma la gran cantidad de agentes con los cuales se cuenta y la gran plaza lo cual le permite estar más cerca a sus clientes.

- Es imprescindible terminar de desarrollar las plataformas digitales que permitan dar a este segmento mayores beneficios, tales como el Servicio de Prevención con cursos a distancia.

\section{c. Red Digital:}

- Este canal comenzó vendiendo productos para personas, recién comenzando a comercializar el SCTR desde el 2016.

- Se captan a los clientes que entran a la compañía a través de su página WEB o que buscan a través de buscadores.

- Similar al SOAT que se puede emitir directamente en línea, Mapfre esta buscando que el cliente final pueda emitir directamente de su WEB, para lo cual está haciendo el desarrollo informático que estará listo a fines del 2018.

- Se decidió apostar por estrategias competitivas de Penetración de mercado ya que se aumentó el número de agentes que comercializan el SCTR buscando de esta forma 
aumentar la participación la cual representa el $1.1 \%$ de las ventas pero que se encuentra en constante crecimiento y con apoyo de inversión por parte de la compañía para explotar este canal.

- Esta red se encuentra en una etapa de introducción.

d. Licitaciones:

- Se decidió utilizar la estrategia de Desarrollo de Nuevos mercados ya que actualmente se concentra en grandes cuentas del Estado, licitadas desde Lima, cuyas tasas no están siendo rentables al licitarse anualmente.

- Se recomienda llegar con más fuerza a provincias ya sea a través de Municipalidades o Gobiernos Regionales.

- Para lo anterior Mapfre debe invertir en personal, pues actualmente no tiene capacidad operativa dentro de las agencias ya que las Licitaciones deben cumplir con toda la parte documental para ser presentadas y requieren especial cuidado para no dañar la imagen de la compañía.

e. Corredores Lima y Provincia:

- Se decidió utilizar la estrategia de Penetración de mercado buscando aumentar la participación de mercado aprovechando la gran cantidad de corredores de seguros con los que se cuenta dentro de Lima y en Provincias.

- La gran distribución geográfica de la red de oficinas, es una de las principales ventajas competitivas de Mapfre, que le permite estar cerca físicamente de los corredores y clientes finales, pudiendo atenderlos con calidad y cercanía.

- Cabe destacar que a diferencia de la competencia en las oficinas de Mapfre a nivel nacional se pueden llevar a cabo todos los procesos de seguros, desde emisión, constancias, facturación, cobranza, pago de siniestros entre otros.

- Al pagar menores comisiones que la competencia como por ejemplo Positiva, es conocido que no todos los corredores querrán trabajar con Mapfre, pues muchos de ellos producen con la compañía que les da mayor comisión.

- Es imprescindible enfocarse en aquellos corredores leales y fidelizados a los cuales se les puede dar planes de incentivos por crecimiento y rentabilidad, apoyándolos operativamente y ayudándolos con la fidelización de su cartera. 


\subsubsection{Ciclo de Vida del Producto}

Según Kotler y Keller (2016), el ciclo de vida de un producto se divide en cuatro fases conocidas como introducción, crecimiento, madurez y declive.

Figura 3.7

Ciclo de vida del producto

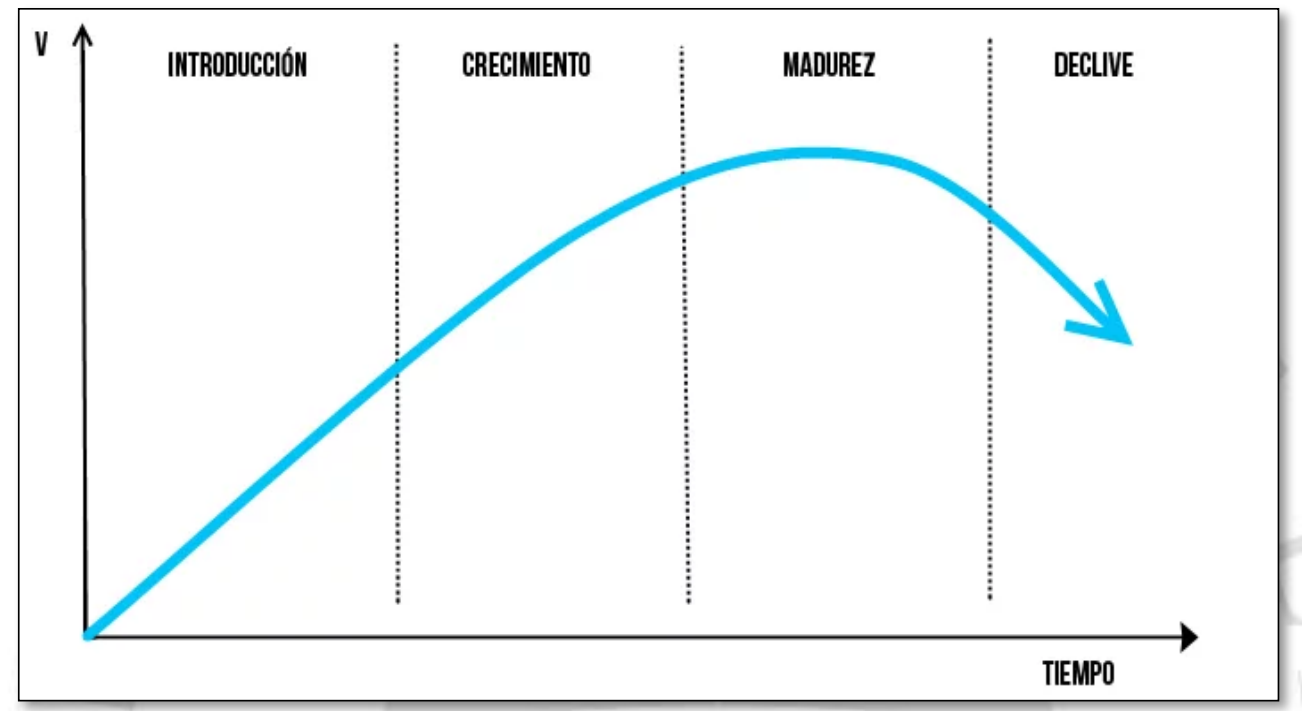

Fuente: Mapfre Perú (2018)

Dada la problemática y el tiempo del producto en el mercado (20 años) este se encuentra de forma general en una etapa de madurez, según Kotler y Keller (2016), en su libro Dirección de Marketing, en este periodo las utilidades se estabilizan o disminuyen por lo cual se produce una disminución de las ventas a causa del conocimiento del producto, en este caso la Ley obliga desde hace más de 20 años a todos los trabajadores que realizan actividades de alto riesgo a contar con el SCTR, dada la disyuntiva económica del país, la fuerte guerra de precios y las cuentas ya ganadas que generan utilidad rentable en el tiempo, el producto se ubica en la etapa de Madurez, buscando de esta forma proteger la posición en el mercado y buscando nuevas cuentas que generen una utilidad sostenida. 


\section{CAPITULO IV: ANALISIS DE RESULTADOS}

La industria del SCTR facturó el año 2017 S/.656,28 Millones, con un crecimiento del $2.9 \%$ con relación al año 2016 .

Hasta el año 2014 el ritmo de crecimiento del mercado era superior al 10\% anual, a partir del año 2015 se evidencia un freno en él crecimiento por debajo del 5\%, siendo el crecimiento el 2016 casi nulo.

Esta desaceleración se dio motivada por los factores económicos y políticos que afectaron al país sobre todo a grandes obras de infraestructura y postergación de nuevas inversiones en diversos sectores como transportes, energía, minero, además del fenómeno del niño costero el año 2017.

Es así que dentro de la cartera de SCTR de Mapfre las Grandes Cuentas pasaron de conformar el 53.9\% de sus ventas al 40.9\% entre el 2014 al 2017.

En el segmento corporativo se cuenta con renovación mayor al $90 \%$ en el segmento Corporativo. Las otras compañías del mercado son seguidoras de Mapfre en este servicio. La unidad de Riesgos del Trabajo (SCTR), cuenta con una nota de 8.76 sobre 10 en la medición de calidad en el primer semestre del 2018 lo que la califica como muy buena.

Mapfre es la cuarta marca más empática del IBEX 35 según el estudio Top Emphatic Brands 2018, realizado por la consultora SUMMA.

Mapfre es la $31^{\mathrm{a}}$ compañía aseguradora más valiosa del mundo según el ranking que elabora la consultora internacional Brand Finance, en el que analiza las 100 aseguradoras más valiosas,

Mapfre es la novena marca más valiosa de España y líder en la industria aseguradora en 2018, registradando un crecimiento de la marca MAPFRE de un 17\% hasta los 2.794 millones de euros evalúa la facturación, los beneficios y el impacto emocional. 


\section{CONCLUSIONES}

- El Seguro Complementario de Trabajo de Riesgo (SCTR), es un seguro obligatorio que cubre contra accidentes de trabajo y enfermedades profesionales a los trabajadores de las empresas obligadas por Ley, tales como Construcción, Minería, Metal Mecánica, Pesca, Puertos, entre otras de alto riesgo.

- El SCTR es un seguro que cubre a Personas y es contratado por Empresas para sus trabajadores. Son cuatro compañías de seguros del mercado que comercializan el SCTR.

- Rímac y Pacífico utilizan una estrategia de diferenciación dando soluciones integrales a todas las necesidades de seguro de la empresa, se apoyan en la fortaleza financiera de sus respectivos grupos económicos (Breca y Credicorp) y están muy enfocados en los clientes corporativos, Positiva está usando una estrategia de liderazgo en costos sin embargo no tienen la capacidad para brindar el servicio en forma ágil y sobre todo cubrir los siniestros eficientemente.

- Mapfre se ha mantenido como segundo del mercado, muy cerca del líder Rimac con una participación cercana al 29\%, con un alto grado de fidelización de sus clientes.

- Mapfre busca posicionarse como: La aseguradora global de confianza, establece como misión: actuar como un equipo que trabaja para avanzar constantemente en el servicio y para desarrollar la mejor relación con clientes, distribuidores, proveedores, accionistas y la Sociedad.

- Sus principales fuentes de ventaja competitiva en el SCTR son:

a) La red de oficinas y distribución a nivel nacional (60 oficinas), que permite a Mapfre llegar de manera directa al cliente final a través de sus redes de venta propias y permite la atención de los corredores medianos y pequeños a nivel nacional, además de la atención específica para Grandes Cuentas.

b) Los sistemas, que le permite una operativa eficiente en la emisión, cobranza y atención de siniestros, permitiendo llegar a segmentos como las Pymes que tiene alto costo de transacción para corredores y compañías del mercado.

c) El Servicio de Prevención de Riesgos Laborales, que le ha permitido posicionarse como expertos en prevención, fidelizando a los clientes y bajando la siniestralidad. 


\section{RECOMENDACIONES}

- Una herramienta fundamental que utiliza Mapfre es que cuenta con un sistema de medición de calidad del servicio, donde se miden estándares de cumplimiento para todas las unidades del grupo y principales procesos.

- Se recomienda seguir con la medición de la cortesía y el trato con el cliente t

- Se concluye que hay oportunidades de mejora especialmente en los clientes pequeños como las Pymes, dichas brechas dado el alto costo que representa llegar a dichos clientes en comparación con las primas que pagan, solamente pueden ser superadas mediante medios digitales y servicios WEB.

- Dada la problemática del mercado de SCTR se decidió por utilizar estrategias competitivas de crecimiento para cada canal de ventas individualmente y en algunas estrategias defensivas, en base a su registro histórico y por la presente investigación se concluye:

a) Grandes cuentas: Al ser las grandes empresas del mercado donde se da la mayor batalla comercial y donde están concentrados Rímac y Pacifico, apostar por diversificar el crecimiento a través de la red de oficinas a nivel nacional y las redes propias. Es así que se recomienda utilizar estrategias defensivas como la de defensa móvil, Diversificación de mercado. También se recomienda la estrategia de Defensa Preventiva, atacando cliente objetivo de la competencia.

b) Red Plaza y Red SCTR: Se decidió utilizar la estrategia de Desarrollo de Nuevos Mercados buscando llegar a pequeñas y medianas empresas Pymes, que actualmente no cuentan con el producto, dado el alto grado de informalidad en el país $(70 \%)$. Además las redes propias llegan a provincias y clusters económicos, aprovechando de esta forma la gran cantidad de agentes con los cuales se cuenta y la gran plaza lo cual le permite estar más cerca a sus clientes.

c) Canal Digital: Se debe terminar de desarrollar las plataformas digitales que permitan dar a este segmento mayores beneficios, como el autoservicio. Por estrategia Mapfre ha comenzado a utilizar este canal (199 agentes) para los productos de personas individuales (autos, salud, vida, decesos). 
d) Licitaciones: Se decide utilizar la estrategia de Desarrollo de Nuevos mercados ya que actualmente se concentra en grandes cuentas del Estado, licitadas desde Lima, cuyas tasas no están siendo rentables al licitarse anualmente. Se recomienda llegar con más fuerza a provincias ya sea a través de Municipalidades o Gobiernos Regionales.

e) Corredores Lima y Provincia: Se decidió utilizar la estrategia de Penetración de mercado buscando aumentar la participación de mercado aprovechando la gran cantidad de corredores de seguros con los que se cuenta dentro de Lima y en Provincias. La gran distribución geográfica de la red de oficinas, es una de las principales ventajas competitivas de Mapfre, que les permite estar cerca físicamente de los corredores y clientes finales, pudiendo atenderlos con calidad y cercanía. Cabe destacar que a diferencia de la competencia en las oficinas de Mapfre a nivel nacional se pueden llevar a cabo todos los procesos de seguros, desde emisión, constancias, facturación, cobranza, pago de siniestros entre otros. Al pagar menores comisiones que la competencia como por ejemplo Positiva, es conocido que no todos los corredores querrán trabajar con Mapfre, pues muchos de ellos producen con la compañía que les da mayor comisión. Por eso es imprescindible enfocarse en aquellos corredores leales y fidelizados a los cuales se les puede dar planes de incentivos por crecimiento y rentabilidad, apoyándolos operativamente y ayudándolos con la fidelización de su cartera.

Se recomienda hacer uso de publicidad ATL para aumentar el conocimiento de la marca en el segmento meta, así como publicidad BTL de tal forma que se pueda aumentar la participación y presencia de mercado que se tiene aún más. 


\section{REFERENCIAS}

David, F. R., David, F. R., y Hernán D'Borneville, E. J. (2017). Conceptos de administración estratégica (15. ${ }^{\mathrm{a}}$ ed.). México D.F.: Pearson Educación.

Domínguez Doncel, A. y Muñoz Vera, G. (2013). Métricas de márketing (2. ${ }^{a}$ ed.). Madrid: ESIC.

Hoffman, D. K. (2011). Marketing de Servicios: Conceptos, Estrategias y casos (4. $\left.{ }^{\mathrm{a}} \mathrm{ed}.\right)$. México D.F.: Cengaje Learning.

Kotler, P. y Keller, K. (2016). Dirección de Marketing (15. a ed.). Mexico D.F.: Pearson Education.

Kotler, P. y Roberto, E. (2009). Marketing Social (5. a ed.). México D.F.: Diaz de Santos.

Lovelock, C. H., y Wirtz, J. (2015). Marketing de servicios: Personal, tecnología y estrategia (7. ${ }^{a}$ ed.). México D.F.: Pearson Education.

Maqueda Lafuente J. y Llaguno Musons J. (1997). Marketing estratégico para empresas de servicios. Madrid: Díaz de Santos

Mapfre Perú. (2017). Informe Tercer Trimestre SCTR. Lima. Autor

Mapfre Perú. (2018). Informe Cierre de año SCTR. Lima. Autor

Munuera Alemán, J. L. y Rodríguez Escudero, A. I. (2010). Estrategias de marketing (2. ${ }^{\text {a }}$ ed.). Madrid: ESIC.

Nagle, T. y Holden, R. (2009). Estrategias y Tácticas de precios. (3. a ed.). Madrid: Person Education.

Porter, M. E. (2015). Ventaja competitiva: Creación y sostenimiento de un desempeño superior (2. ${ }^{\mathrm{a}}$ ed.). Madrid.: Grupo Editorial Patria.

Superintendencia de banca, seguros y AFP. (2017). Competidores directos SCTR. Lima: Autor. 


\section{BIBLIOGRAFÍA}

Equilibrium Clasificadora de Riego. (2016). Informe de Clasificación. Lima: Autor.

Johnston, M. W. y Marshall, G. W. (2015). Administración de ventas (9. ${ }^{\mathrm{a}}$ ed.). México, D.F.: Person Education.

Kotler, P. y Armstrong, G. (2015). Fundamentos de márketing (11. ${ }^{\mathrm{a}}$ ed.). México, D.F: Pearson Educación.

Schnarch Kirberg, A. (2013). Marketing para Pymes: Un enfoque para Latinoamérica (2. ${ }^{\mathrm{a}}$ ed.). México D.F.: Alfa Omega. 